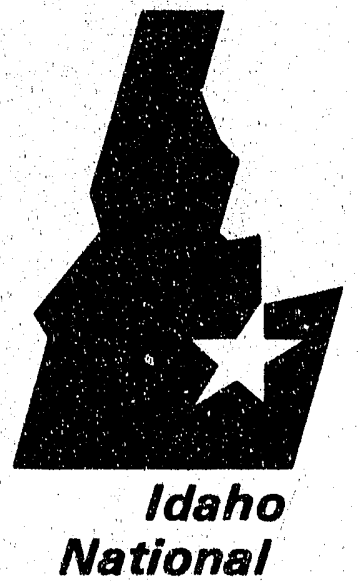

Engineering

Laboratory

Managed by the U.S.

Department

of Energy
$E G G-N E-10137$

December 1991

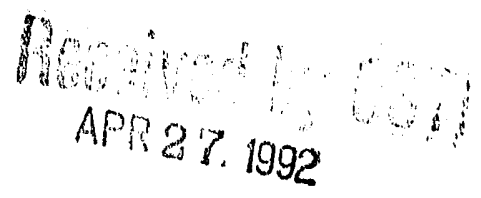

\title{
INFORMAL REPORT
}

VENTURE/PC MANUAL A MULTIDIMENSIONAL MULTIGROUP NEUTRON DIFFUSION CODE SYSTEM VERSION 3
A. Shapiro
H. C. Huria
K. W. Cho

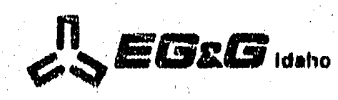

Work performed under DOE Contract No. DE-AC07.761D01570 


\section{VENTURE/PC MANUAL wa92023651}

\section{A MULTIDIMENSIONAL MULTIGROUP NEUTRON DIFFUSION CODE SYSTEM}

VERSION 3

A. Shapiro, H. C. Huria, K. W. Cho

December 1991

UNIVERSITY OF CINCINNATI NUCLEAR ENGINEERING PROGRAM CINCINNATI, OHIO 45221

Prepared for EG\&G Idaho, Inc. Under Subcontract No. C-87-101212 and the U.S. Department of Energy Under Contract No. DE-AC07-76ID01570

Sponsored by DOE Offices of Energy Research and Nuclear Energy
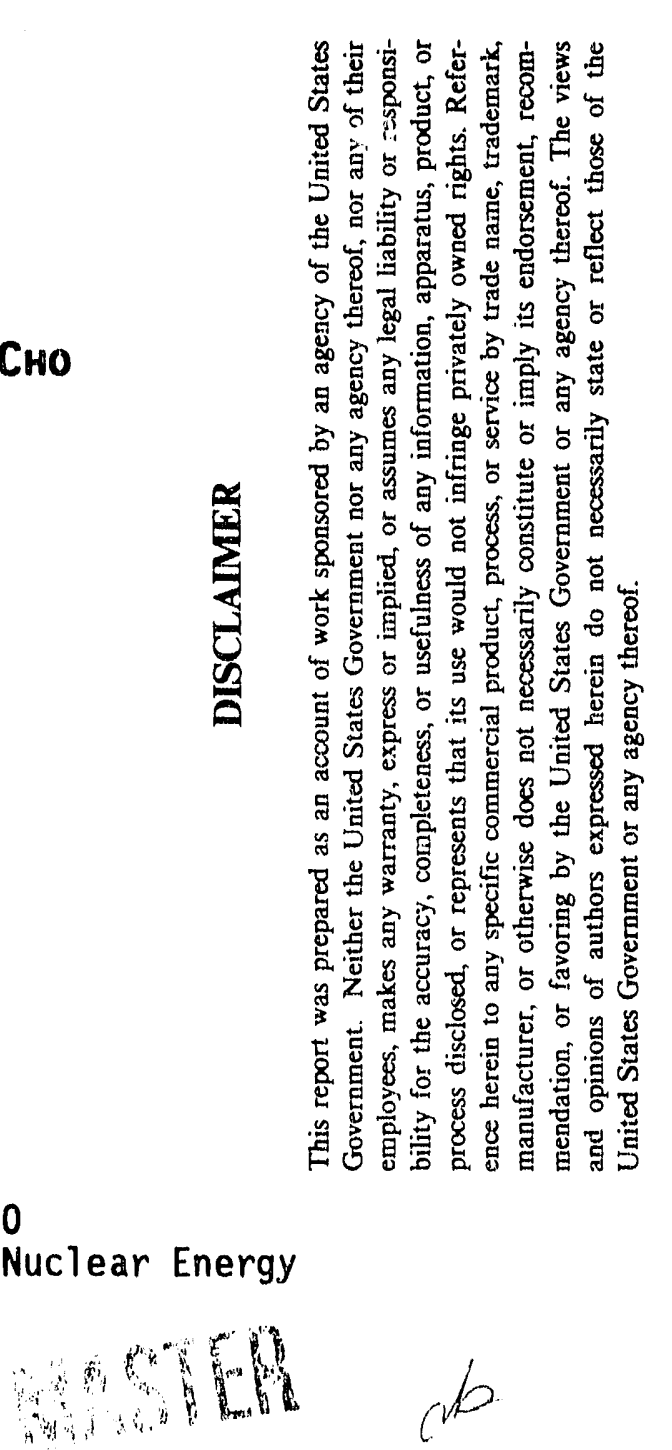
Abstract

Acknowledgement List of Figures VENTURE/PC Code Getting started

Abstract

PART I. DESCRIPTION OF CODE SYSTEM

1. Introduction

2. VenTURE/PC Code system . . . . . . . . . . . . . . . 2

3. Driver.

4. Control Module. . . . . . . . . . . . . . . • • 5

5. Input Processor. . . . . . . . . • • • • . . 6

6. Cross section processor. . . . . . . . . . . . . 6

7. VENTURE Neutronics Module. . . . . . . . . . . . . . . 9

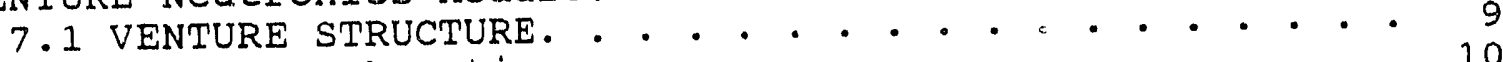

7.2 VENTURE Subroutines. . . . . . . . . . . . . . 10

7.3 VENTURE File Requirements. . . . . . . . . . . .14

7.4 Data Handling Modes. . . . . . . . . . . . . . 15

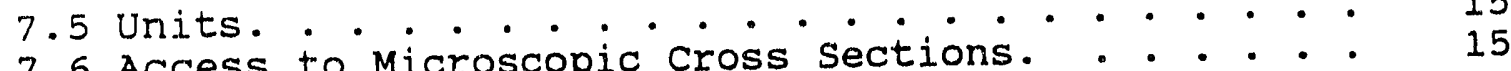

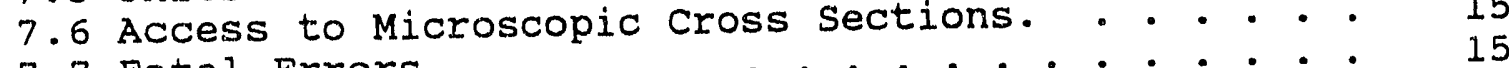

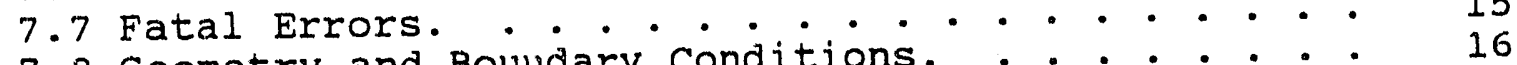

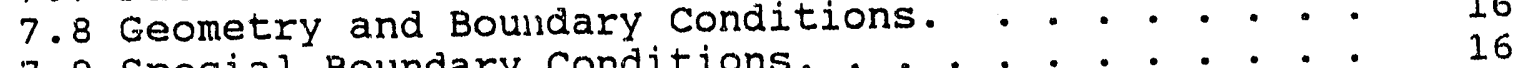

7.9 Special Boundary Conditions. . . . . . . . . . 16

7.10 Types of Problems Solved. . . . . . . . . . . . 17

7.11 Iteration Procedures. . . . . . . . . . . . . . . . . 18

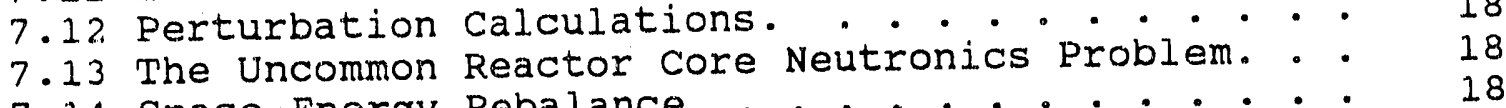

7.14 Space-Energy Rebalance.

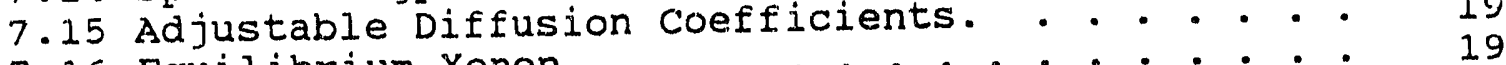

7.16
7.17
Tempulibrium Xenon

8. EXPOSURE Code Module. . . . . . . . . . . . . . . 20 
PART II. DESCRIPTION OF INPUT FOR VENTURE/PC . . . . . . . 24

9. Input structure. . . . . . . . . . . . . . . . . 24

10. Control Module Input. . . . . . . . . . . . . . 26

10.1 Memory Allocation . . . . . . . . . . . . . . . 26

10.2 Using Binary Standard Interface Files as Input. . 27

10.3 Calculational Path. . . . . . . . . . . . . . 28

10.4 Machine Dependent and Miscellaneous Data. . . . . 29

10.5 Example of Input for Control Module. . . . . . . 33

11. Input for Input Processor. . . . . . . . . . . 35

12. Standard Interface Files Required by Modules. . . . . 35

13. Some, Examples of Input Structure. . . . . . . . . . . 39

13.1 NEW2DXY. INP . . . . . . . . . . . . . . . . 39

13.2 NEWBWR. INP . . . . . . . . . . . . . . . . . 42

13.3 Three Theta-R Cases . . . . . . . . . . . . 44

13.4 Exposure Problem. . . . . . . . . . . . . . . . . 46

13.5 Using Standard Interface Files on Input. . . . . 48

14. Relocating Fuel Bundles. . . . . . . . . . . . 50

15. Data Transfer, File Management and Input-output. . . 50

15.1 Standardized Routines. . . . . . . . . . . . 50

15.2 Input and output Files. . . . . . . . . . . . . 51

15.3 Saving of Standard Interface Files. . . . . . . 51

15.4 Scratch and Direct Access Files. . . . . . . . . 52

15.5 Saving of standard Interface File in Text Format. 52

16. Correspondence Between DVENTR and DTNINS. . . . . . . 53

17. Compiler and overlay structure for VENTURE code. . . 56

18. VENTURE/PC Interactive Processor, "VIP". . . . . . . 65

REFERENCES . . . . . . . . . . . . . . . . . . . 67

APPENDIX I FORTRAN LISTING OF DRIVER . . . . . . . 69

APPENDIX IV VENTURE SUBROUTINES . . . . . . . . 76

APPENDIX III. BURNER SUBROUTINES . . . . . . . 86 


\section{Abstract}

VENTURE/PC is a recompilation of part of the oak Ridge BOLD VENTURE code system, which will operate on an IBM PC or compatible computer. Neutron diffusion theory solutions are obtained for multidimensional, multigroup problems. This manual contains information associated with operating the code system. The purpose of the various modules used in the code system, and the input for these modules are discussed. The PC code structure is also given.

Version 2 included several enhancements not given in the original version of the code. In particular, flux iterations can be done in core rather than by reading and writing to disk, for problems which allow sufficient memory for such in-core iterations. This speeds up the iteration process.

Version 3 does not include any of the special processors used in the previous versions. These special processors utilized formatted input for various elements of the code system. All such input data is now entered through the Input Processor, which produces standard interface files for the various modules in the code system. In addition, a standard Interface File Handbook is included in the documentation which is distributed with the code, to assist in developing the input for the Input Processor. 


\section{ACKNOWLEDGEMENT}

This work is a recompilation of codes developed at oak Ridge over a period of several years. In particular, the excellent work and reports of D.R. Vondy, T.B. Fowler, and G.W. Cunningham, who developed the original code at oak Ridge, is hereby acknowledged and credited. Also, the work of R.D. Odell and others at Los Alamos resulting in a generalized Input Processor is acknowledged. This manual is a reorganization of reports received from the Radiation Shielding Information Center or the BOLD VENTURE

code system.

We also acknowledge the Reactor Physics group at INEL, in particular, Dr. D.W. Nigg, for their financial support, and for beginning the task of developing reactor physics and shielding codes for the microccmputer. 


\section{List of Figures}

1. Components of the Computation system...............

2. Calculational Modes of Cross section processor...........8

3. Calculational Flow for VENTURE Neutronics Module.........11

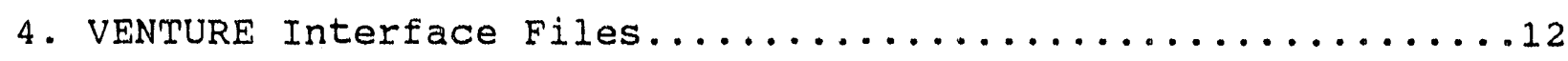

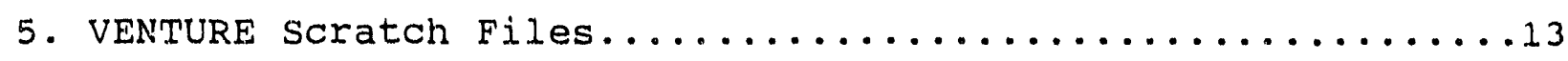

6. User Flow Diagram of BURNER Module................22

7. Interface files required for BURNER Code.................

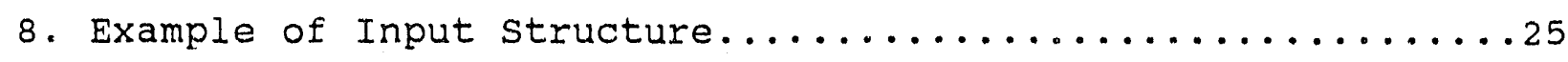

9. User Input Instructions to Control Module CONTROL1........30

10. Example of Input to Control Module....................

11. Module Control Records and Interface Files..............38

12. Input structure for Two dimensional $x-Y$ Problem........

13. Input Structure for BWR Assembly sample Problems.......43

14. Input Structure for Three Theta-R Cases............. 45

15. Input Structure for an Exposure Problem...........47

16. Example of Input with standard Interface files........49

17. VENTURE/PC Overlay structure...................

18. Subroutines in VENTURE/PC overlay structure...........60

19. VIP overlay structure..................... 66 


\section{VENTURE/PC Code Abstract}

1. Program Identification VENTURE/PC is a PC version of that part of the BOLD VENTURE code system developed at Oak Ridge for IBM mainframes, which includes the Control Module, an Input Processor, a Cross-Section Processor, the VENTURE neutronics code, and an Exposure Module which utilizes the BURNER code for depletion calculations.

2. Function The VENTURE code solves the usual neutronics eigenvalue, adjoint, fixed source, and criticality search problems. It treats up to three dimensions, maps power density, and does first order perturbation analysis at the macroscopic cross section level. The Burner code solves the nuclide chain equations to estimate the nuclide concentrations at the end of an exposure time, and also after a shutdown period.

3. Method of Solution The VENTURE module applies the FiniteDifference Diffusion or a simple P1 Approximation. VENTURE uses an outer-inner iteration scheme with several different data handling methods. Overrelaxation is applied to the inner, and outer iterations, and succeeding flux iterates may be accelerated with the Chebychev process. The BURNER code uses a difference formulation based on average generation rates, or a matrix exponential formulation to approximate the solution of the coupled burn-up differential equations, or an explicit solution for simply coupled nuclide chains. Space dependence is included by working with zone averaged fluxes. 
4. Related Material A Control Module, Input Processor, and a Cross Section processor interface with input files to produce standard interface files for use by VENTURE and BURNER. Standard interface files are binary sequential files which follow a prescribed or standardized format.

5. Restrictions The code is variably dimensioned, but the data arrays are limited to 36000 words, or 144000 bytes, to work within the $640 \mathrm{~K}$ memory limit of the present Dos operating system.

6. computer. The code will work on IBM or IBM compatible microcomputers working under the DOS operating system.

7. Running Times Running $t$ imes are variable, and very problem and machine dependent. Many two or one dimensional problems should complete within 30 minutes on an original IBM PC, and in less than half that time on AT type machines. Three dimensional problems should probably be reserved for AT or higher class machines.

8. Programming Language FORTRAN 66 or 77 . The program was originally written in ASA 1966 FORTRAN, but was compiled for the microcomputer with FORTRAN 77.

9. Operating system The program was compiled under DOS 3.1, and should run with earlier versions of DOS.

10. Machine Requirements The program requires about 5 megabytes of disk storage, to hold the executable files and files gen rated by the code. It also requires $640 \mathrm{~K}$ of memory, and a math co-processor. 
11. Authors A. Shapiro, H.C. Huria and K.W. Cho Nuclear Engineering

$$
\begin{aligned}
& \text { Mail Location } 72 \\
& \text { University of Cincinnati. } \\
& \text { Cincinnati, Onio } 45221
\end{aligned}
$$$$
\text { (513) 556-2014 }
$$

12. References "BOLD VENTURE IV, A Reactur Analysis code

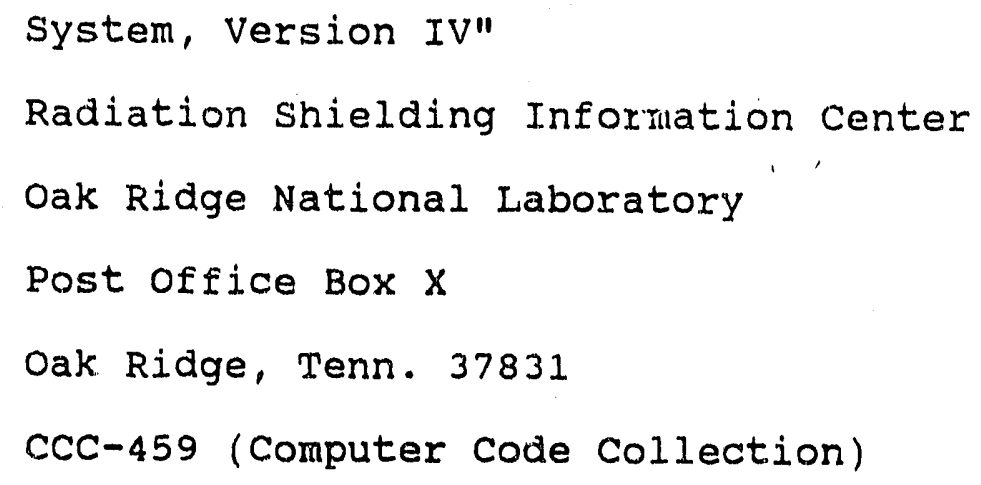

13. Materials Available VENTURE/PC Manual, Standard Interface File handbook, VIP (Venture Interactive (Input) Processor), VENTURE Code System, executable files and source decks on $1.2 \mathrm{MB} 51 / 4$ inch diskettes. 


\section{GEITING STARTED}

VENTURE/PC is a multidimensional, multigroup, neutron diffusion code system, with provisions for processing cross sections, and for calculating burnup. VENTURE/PC is a PC compilation of part of the BOLD VENTURE code system, developed over several years at Oak Ridge National Laboratory. The conversion to the microcomputer was done as part of the INEL program for establishing a PC based reactor physics package.

VENTURE/PC is a very large code system, with many input options, which makes the code complicated. The executable code requires almost 3 million bytes for storage, and requires almost all of the maximum Dos memory of $640 \mathrm{~K}$ to run. The code was linked with overlays, with the linked executable file being about $522 \mathrm{~K}$, but file buffers, and the operating system take up most of the remaining memory within the $640 \mathrm{~K}$ DOS limit. In addition, the code comes with an interactive input processor, VIP for VENTURE Interactive Processor, which requires about 900,000 bytes for storage. VIP was also linked with an overlay structure to allow it to run with DOS. Additional disk space must be made available for files. Thus, to run VENTURE with the interactive input processor, a subdirectory of about $5 \mathrm{MB}$ will be required. The VENTURE/PC code system was compiled under DOS 3.1 with the Lahey FCRTRAN-77 compiler, version 2.22. Overlay linking was accomplished through the Phoenix PLINK86 Plus overlay linker, version 2.24 . 
To run VENTURE/PC, the CONFIG.SYS file on the hard disk root directory should be set for FILES $=50$ and BUFFERS $=10$. In addition, to run VIF the ANSI.SYS file from DCS should be placed on the root directory, and the Iine DEVICE=ANSI.SYS should be added to the CONFIG.SYS file. The system should be booted with these configuration specifications.

Prior to running any problems, the input file for the problem should be copied to the file VENTURE. INP. The output will be written to the file VENTURE.OUT. Several sample problems are given with the code. They all have names with the. INP extension. They can be copied to the VENTURE subdirectory for checking the VENTURE operation.

All standard interface files generated during a run are maintained by name. Text versions of standard interface files are retained on option in the file named STFILE.TXT, which may be edited with any good PC editor.

The file F77L.EER is now included with the code package. This file should be placed on the VENTURE subdirectory. It will provide statements associated with FORTRAN errors, such as improperly formatted input. It is part of the Lahey FORTRAN compiler package. 
PART I. DESCRIPTION OF CODE SYSTEM

\section{Introduction}

VENTURE/PC is an IBM-PC or compatible microcomputer version of the BOLD VENTURE [1] system of connected codes or modules used to analyze the core of a nuclear reactor by applying multigroup diffusion theory. The code system can analyze 1, 2, or 3 dimensions in various geometries. Variable dimensioning is used throughout the codes, which allows for any number of energy groups and mesh points, with the limitation that the problem fit into core memory. Upscattering as well. as downscattering is accommodated by the codes. A depletion module is included for burnup calculations.

An important feature of this code system is that each

code module receives input from, and writes output to, standard interface files. Standard Interface Files (SIF's) are unformatted binary sequential files which have been specified as to format and structure by the committee on computer code coordination [2], or CCCC. An Input Processor [3] reads standard interface card image (or ASCII) format, and converts the input to standard interface files for use by the code modules. Version 3 of VENTURE/PC differs from previous versions in that all special processors have been removed from the code system. These special processors were designed to read formatted input developed for the various code modules prior to CCCC standardization. All input for the code modules in version 3 is accomplished through the Input Processor. 
A Standard Interface File Handbook which accompanies the documentation should help significantly in developing the input.

\section{VENTURE/PC Code SYstem}

The structure of version 3 of VENTURE/PC is shown in Figure 1. It includes a Driver, a Control module, an Input Processor, a Cross Section Processor, and the two main calculational modules VENTURE and EXPOSURE.

The Driver reads the input data on the file VENTURE. INP. All input data must reside on the file VENTURE. INP prior to making a run. To store multiple input data sets on the same disk, each data set should have its own unique name. If the data set is to be used to make a run with VENTURE/PC, it should be renamed or copied to VENTURE.INP. The Driver first calls the control Module which initializes a file catalog and a control file. All interface files are cataloged as to name, unit number and version number, and must be recorded on the catalog file on unit 09. The standard interface file CONTRL, which is initialized by the control Module, contains records of control information required by the modules for selecting various options or calculational pathways. It is written on unit number 10. Upon return from the Control Module, the Driver calls the other modules in an order specified by the control Module. 
The primary function of the cross section processor is to convert isotope ordered cross sections in an ISOTXS file, to group ordered cross sections in a GRUPXS file, as required by VENTURE.

The VENTURE neutronics module calculates the neutronics of a problem, while the EXPOSURE module solves the isotopic rate equations for number density variations associated with fuel burnup and fission product buildup.

The numbers associated with the modules on Figure 1 are the input identification numbers for these modules. 


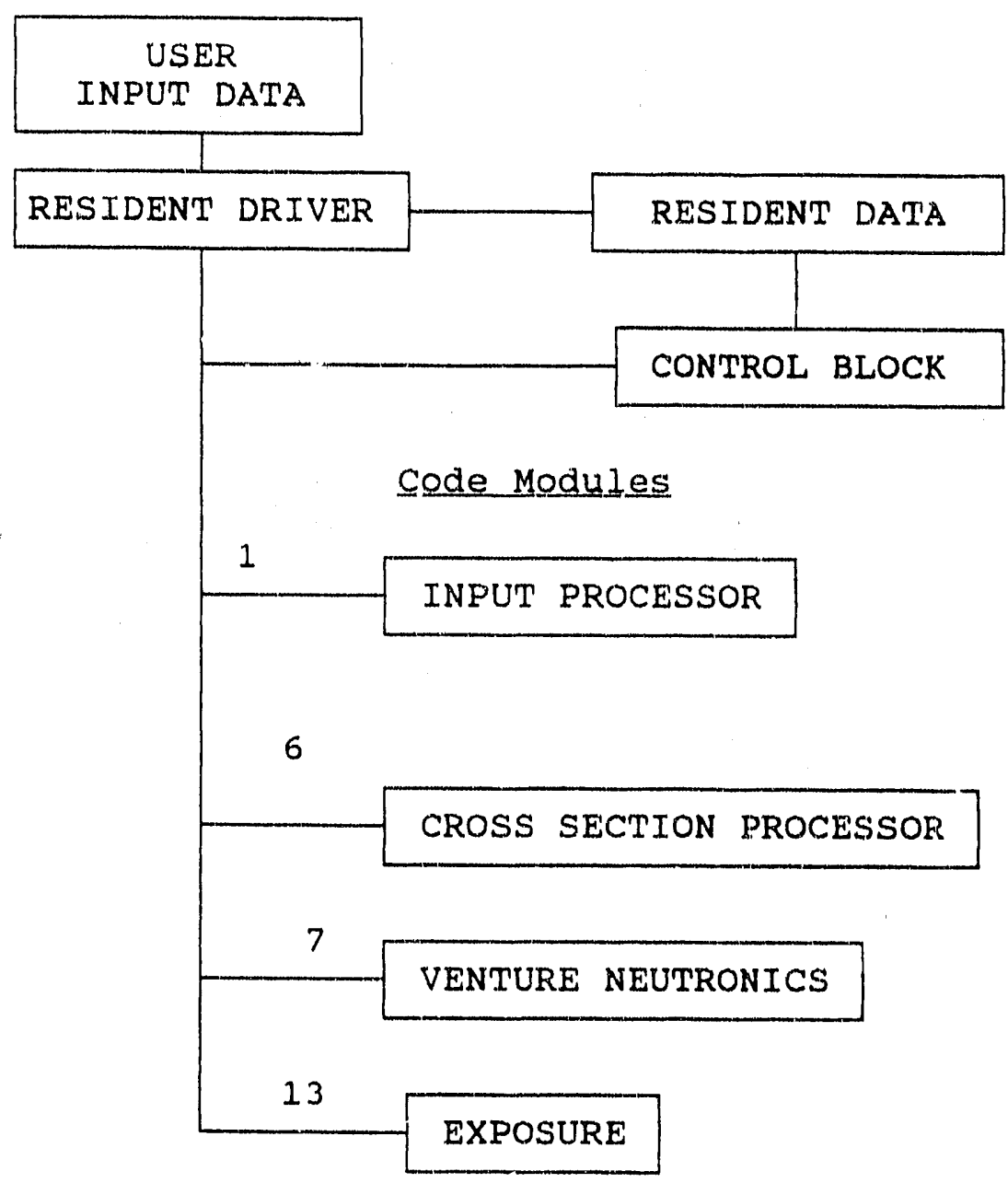

Figure 1. Components of Computation System (From Reference 1) 


\section{Driver.}

The Driver used for VENTURE/PC was established from the partial FORTRAN version of the Los Alamos Driver given in reference [4]. The detailed FORTRAN Iisting of the Driver developed for this work is given in Appendix $I$. The function of the Driver is to first call the Control Module, and read that block of data associated with the Control Module on the input file, VENTURE.INP. The VENTURE.INP file is assigned to unit 1. This Control Module data block is then written on unit 5, for the Control Module to access. This procedure of reading data blocks from the input file, and overwriting the data on unit 5 is done for all input sections. Upon return from the Sontrol Module, The Driver calls the Input Processor and/or the VENTURE neutronics module as specified in the control file. The Input Processor develops all necessary standard interface files required to run the other modules. The other modules required by the problem are then called by the Driver in the sequence given in the control data block.

\section{Control Module.}

The primary functions of the Control Module are to initialize the file which catalogs the standard interface files on unit 9, initialize the standard interface file CONTRL on unit 10, set the problem data storage in memory, identify standard interface files to be used initially, and perform wrap up procedures when a problem prematurely aborts or when it finishes the calculation 
correctly. The catalog file is referenced by the various modules to obtain the unit numbers for standard interface files required by that module. The CONTRL file contains global information records pertinent to the problem, and a specific record for each computational module. The individual records on the CONTRL file for the computational modules are developed by the Input processor. Computational modules read the applicable control information on these records from the CONTRL file when they are accessed.

5. Input processor.

The input processor was developed at Los Alamos [3], and has the function of converting ASCII or BCD input into standard Interface files. The ASCII or BCD input is structured in the same manner as the standard Interface Files. See the "Standard Interface File Handbook" for a more detailed discussion of Standard Interface Files and the Input Processor.

6. Cross Section Processor.

The cross section Processor is documented in reference

[5]. A primary function of this processor is to convert a nuclide ordered ISOTXS file to a group ordered GRUPXS file required by the VENTURE neutronics module. It can also create a nuclide ordered file from the ORNL CITATION code forinat, update an existing nuclide ordered file, and merge two existing nuclide ordered files. The processor has the capability of creating nuclide mixtures and macroscopic cross sections in the nuclide ordered format. It can handle up to 1000 energy groups, 500 nuclides and a Legendre expansion order as high as 20. The capabilities and variations of 
this processor are summarized in Figure 2 . It reads the records labeled XCPINS and DVRINS on the CONTRL file to determine the path to follow.

\subsection{CITATION Cross sections.}

The CITATION code [6] was the prcursor to VENTURE, and many macroscopic cross section sets are available in CITATION format. A Special processor, DCMACR [1], converts the CITATION macroscopic cross sections to microscopic cross sections, and writes the microscopic cross sections on unit 8. The Cross section Processor can then process the microscopic cross section set, and convert the set to a form which can be used by the VENTURE neutronics module. The code DCMACR is provided as a separate code with the VEN'TURE/PC version 3 package. It must be used to process CITATION cross sections before VENTURE/PC is run, and should reside on the same subdirectory as VENTURE/PC. 


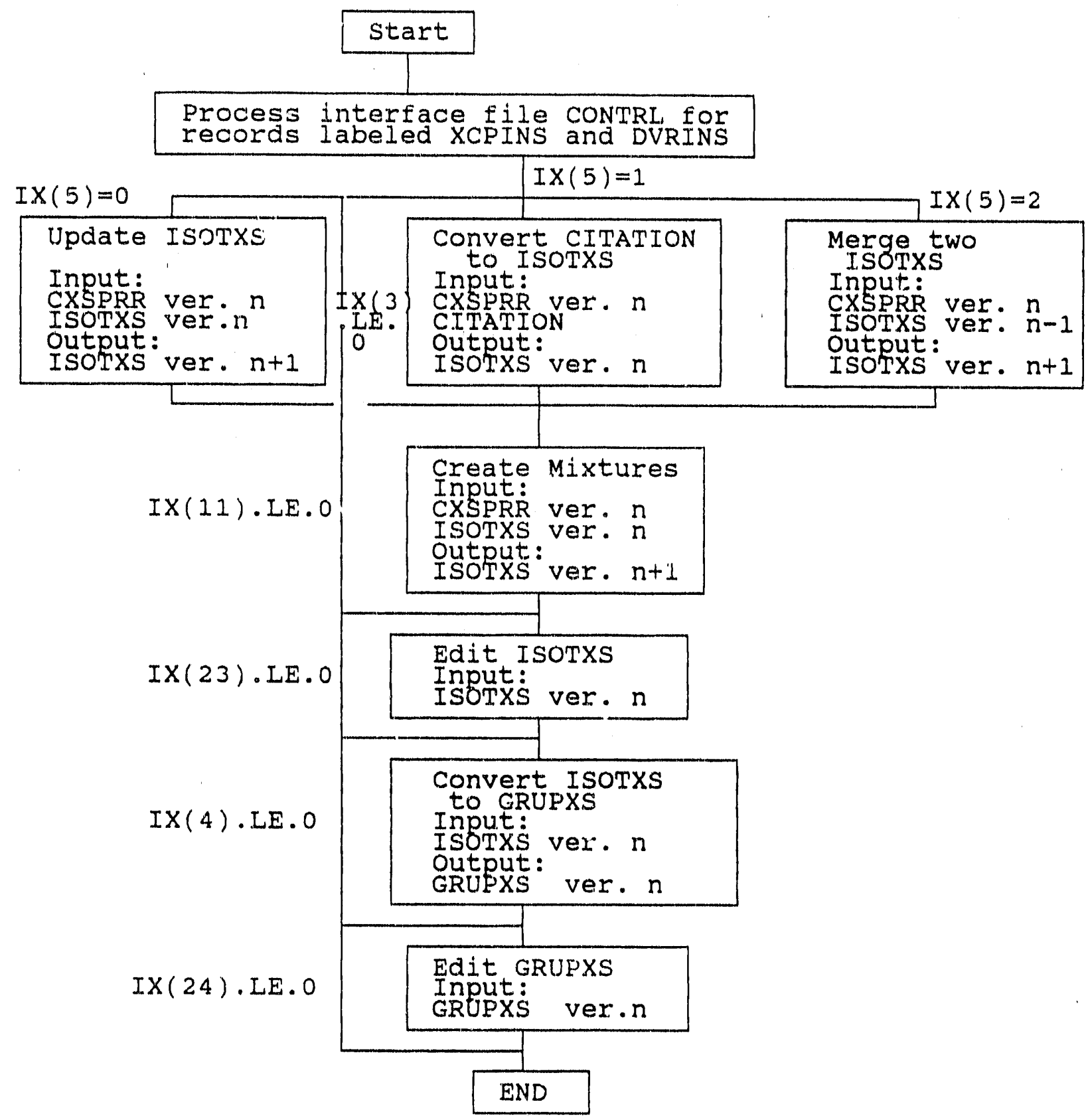

Note: Ver. $n$ refers to the current latest version at that stage of processing.

Figure 2. Calculational Modes of Cross section Processor (from ref. 5) 
2. VENTURE Neutronios Wodule.

The VENTURE module calculates the neutronics of a given problem and is the main module of the code system. Its primary documentation is reference [5], with VENTURE additions given in reference [7]. The interested reader can find the details of the VENTURE code in these references. An outline of the code will be reproduced here.

\subsection{VENTURE STRUCTURE.}

A flow chart for the calculational procedure is shown in Figure 3. The necessary macroscopic cross sections and equation constants must be calculated from the data given in the standard interface files used for input. After the procedures are initialized and scratch files prepared, an outer iteration loop is started. In criticality problems, the fission source and inscatter source are then calculated to provide the source term for the inner iteration. The inner iteration loop is then done for each group, with accelerated overrelaxation used to speed convergence. The $k_{\text {ore }}$ eigenvalue is calculated and the iterated results edited. The convergence criteria are tested, and if convergence is not achieved, the outer iteration loop is repeated. If a direct search problem was specified, the formulation is constructed as an eigenvalue problem, with the eigenvalue as a multiplier on the search parameters of interest (e.g., buckling or dimensions, or nuclide concentrations). The desired $k_{\text {arf }}$ is kept constant. This eigenvalue multiplier is evaluated upon the completion of the inner iteration for each energy group. Thus, for direct search problems, 
the search parameters are estimated after the inner iterations, without the nesessity of an outer iteration. A loop to upgrade eross sections is made after the inner iteration, if a direct search on nuclide concentrations was specified. The indirect search loop changes cross sections or dimensions after the outer iteration, to effect a change in $k_{\text {arr, }}$ until the desired $k_{\text {orr }}$ is achieved. Thus, in the indirect search analysis, both the search parameters and $k_{\text {orf }}$ are changed, and this can only be done through an outer iteration. Upon completion of the outer iteration, the interface files of flux and power density are written, and the results are edited and updated. If an adjoint problem is required it is then done, after which perturbation integrals and importance maps can be generated.

\subsection{VENTURE Subroutines.}

The VENTURE subroutines, as taken from reference [5], are shown in Appendix II. They are grouped together in this Appendix as to function.

\subsection{VENTURE File Requirements.}

The standard interface files used by VENTURE are shown in Figure 4 , along with the files which can be generated by the code on option. The scratch files with their associated unit numbers are shown in Figure 5. Additional information regarding the individual file records is given in reference [5]. 


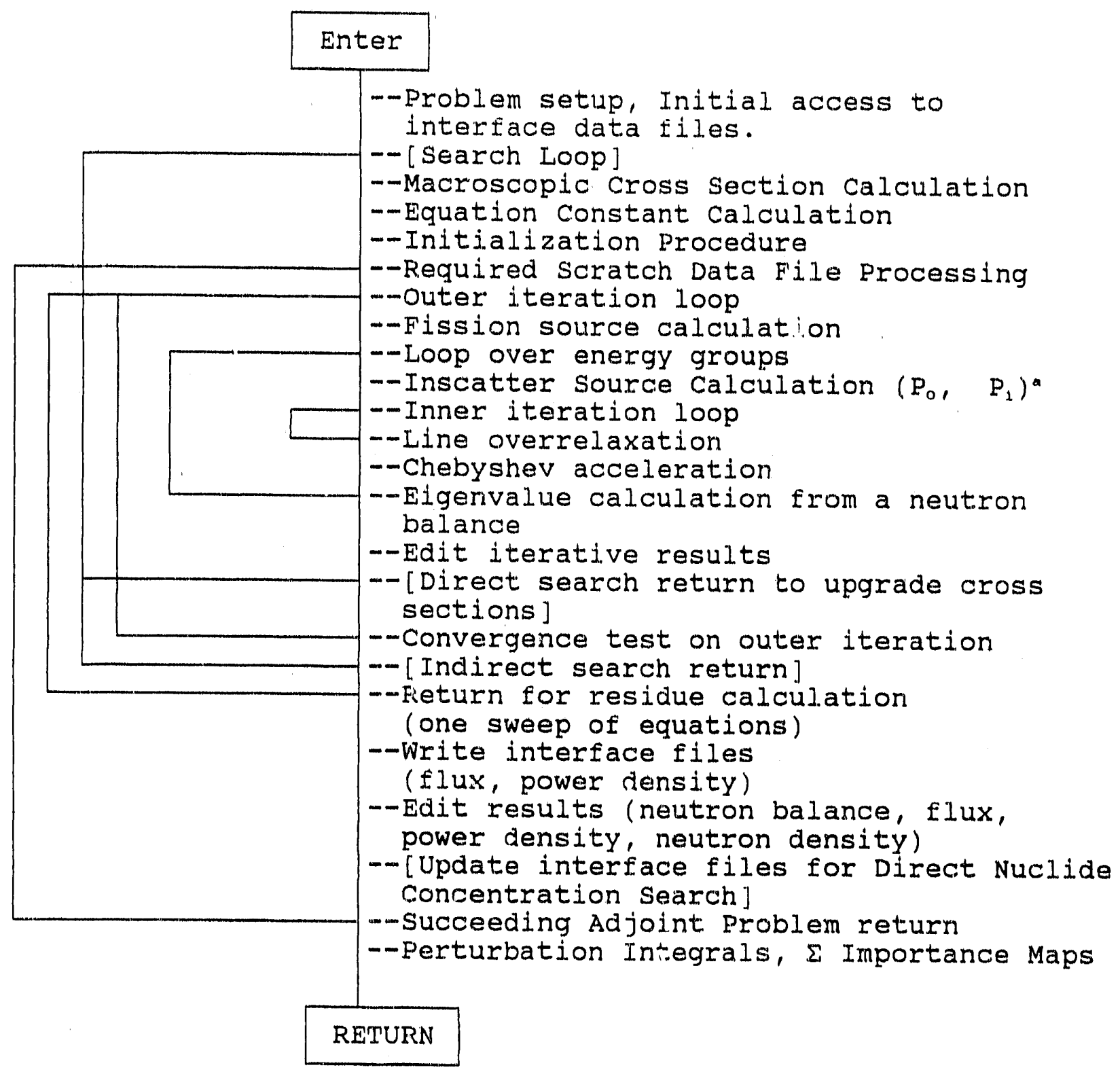

- The inscatter source calculation is normally done outside the inner iteration loop; however, in one data handing mode this source is calculated inside the inner iteration loop to minimize data transfer.

Figure 3. User Flow Chart, VENTURE Finite-Difference Diffusion Theory Neutronics Code Block, (from ref. 6) 


\section{VENTURE Interface Files}

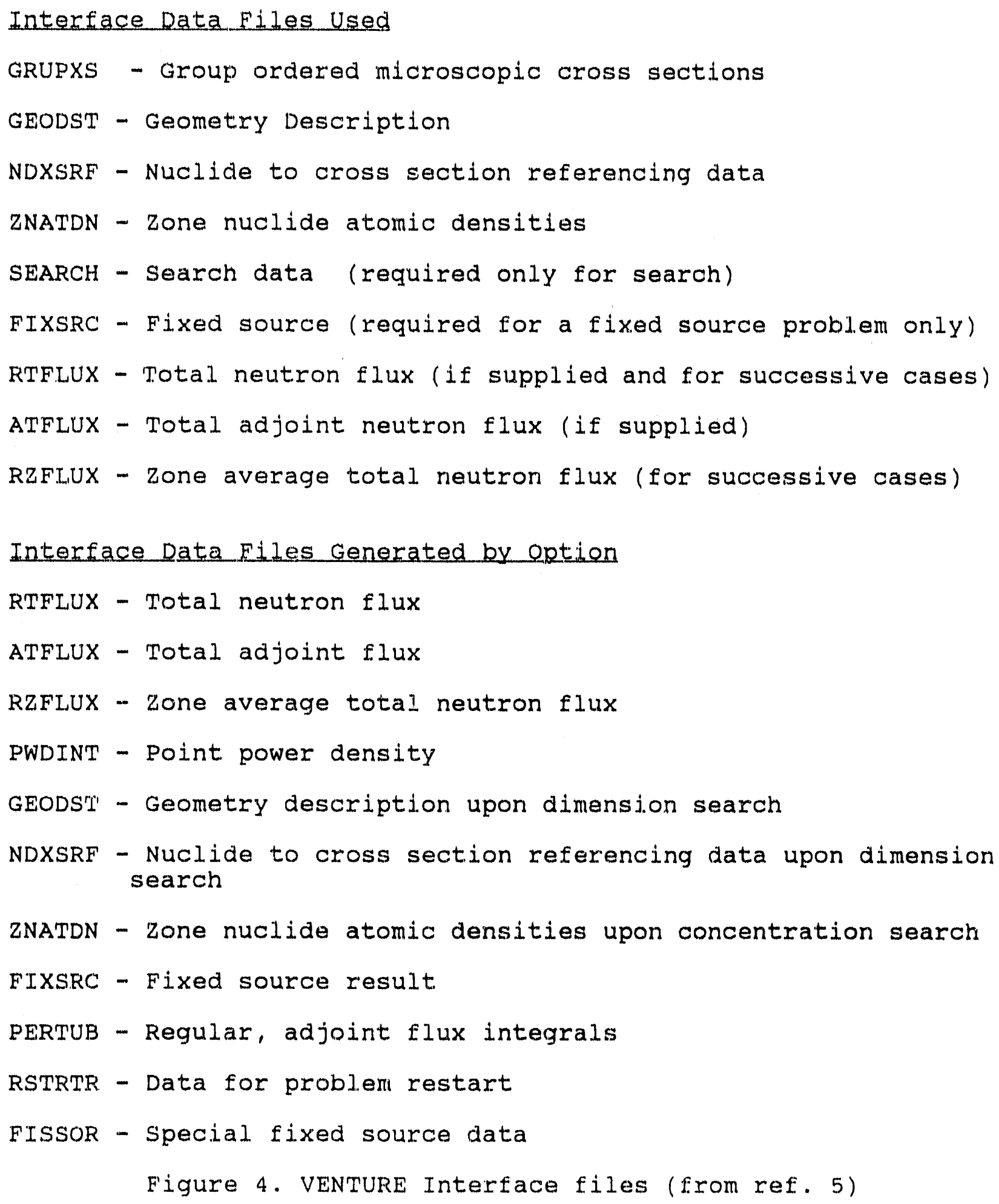


Scratch Files by Unit Number

21

Macroscopic scattering cross sections

22

principal macroscopic cross sections

23 (Direct Access) Equation coupling constants in space, normally not used

24 (Direct Access) Total neutron flux

27 (Direct Access) FIux copy

28 (Direct Access) Flux copy

2.9 (Direct Access) Del dot $J$ times volume (current in the $P_{1}$ sense

40 (Direct Access) Equation constants

41

Fixed source

42

Fission source

43

Total source

44

Neutron balance data

45

Miscellaneous ${ }^{b}$

46

Miscellaneous

47

Search data, misc.

b By miscelianeous is meant that these files are generally used to store different information at different stages of a calculation, but the required storage space is usually not large relative to those for which requirements are given in detail.

Figure 5. VENTURE Scratch Files (from ref. 5) 


\subsection{Data Handling Modes.}

There are several different methods of storing the necessary flux and coupling constant data built into the VENTURE code module. These are:

Al stored Mode. In this mode, all data necessary to complete a calculation is stored in memory. There is little if any data transfer between disk files and memory. This mode can only be used for small problems with few space-energy points.

Space Stored Mode. This is the preferred mode for problems of moderate size, which should apply to most problems which can be run by VENTURE/PC. The equation constants, flux values, and the necessary source values to complete a one group inner iteration for the flux values at each mesh point are stured in memory. To obtain source values, the flux values and scattering data must be read from disk files between iterations.

Multirow stored Mode. This is a data handing technique for two dimensional problems. Data for only several rows of fluxes for a single group are stored in memory, thereby reducing the memory required to complete an inner iteration.

Multiplane stored Mode. In this mode, data for several

planes of a three dimensional problem are stored in memory. Storing equation constants and source values for $n$ planes, and flux values for $n+2$ planes, allows inner iterations to be done for $n$ planes, with one access of equation constants, one access of old filux values, and one transfer of new flux values for each plane of the problem. 
One Row Stored Mode. For large three dimensional problems with many space points, it may be necessary to limit the data in memory to that required to complete an inner iteration for a single row. Storage is allocated for the necessary five rows of flux values and equation constants to complete the inner iteration. This method applies only to three dimensional problems, and is slow due to the many disk transfers required to complete a problem. 7.5 Units.

Dimensions are in centimeters, nuclide densities in atoms/barn-cm, microscopic cross sections in barns, and macroscopic cross sections in $\mathrm{cm}^{-1}$.

\subsection{Access to Microscopic Cross Sections.}

Except for nuclide concentration searches, the microscopic cross sections and nuclide densities are accessed only once. All subsequent calculations use macroscopic cross sections which are calculated in the beginning.

\subsection{Fatal Exrors.}

Fatal errors are of the following types:

Errur Number 666 - error encountered in processing interface data files;

Error Number 444 - data transfer errors;

Error Number 555 - other interpreted errors and system errors. 


\subsection{Geometry and Boundary Conditions.}

The one dimensional geometries available are the slab, infinitely high cylinder, and sphere. The two dimensional geometries include $X-Y, R-Z$, Theta $-R$, equilateral triangle, $T$, and equilateral hexagon, H. Three dimensional geometries include $X-Y-Z$, Theta-R-Z, $T-Z$, and $H-Z$. Left boundary conditions include: zero flux, reflected, extrapolated, and repeating. Right boundary conditions are zero flux, reflected, extrapolated, repeating, and rotational symmetry conditions. For multidimensional problems, additional column and plane boundary conditions must be specified, the latter required for three dimensional problems.

\subsection{Special Boundary Conditions.}

VENTURE allows for some special boundary conditions. These include $90^{\circ}$ and $180^{\circ}$ rotational symmetry for slab and rectangular geometries, and $120^{\circ}$ and $60^{\circ}$ rotational symmetry for corresponding triangular coordinates. Rotations are keyed to the right hand or third side of these geometries. See reference [5] for additional details. 


\subsection{Iypes of Problems solved.}

VENTURE can solve the following types of neutronics problems:

1 - Usual Eigenvalue Problem.

2 - Fixed Source Problem

3 - Adjoint Flux Problem

4 - Direct Buckling Search

5 - Direct Reciprocal Velocity Search

6 - Direct Nuclide Concentration Search

7 - Indirect Searches - Concentrations and Dimensions

\subsection{Iteration Procedures.}

Solutions to eigenvalue and search problems are done through the usual inner-outer iteration procedures. Overrelaxation is applied to speed convergence. Chebyshev polynomials are utilized to obtain overrelaxation coefficients. The eigenvalue is estimated after each outer iteration as the ratio of the total production rate to loss rate. A very detailed discussion of the rather complicated acceleration techniques utilized in VENTURE is given in reference [5]. 


\subsection{Perturbation Calculations.}

VENTURE provides information associated with perturbation calculations. Given forward and adjoint flux solutions, the derivative of $k_{\text {are }}$ with respect to each zone cross section and diffusion constant are calculated and edited on option. The zone integrals of volume times the product of the flux and its adjoint are written on an interface data file for future use. Pointwise importance maps of $v \Sigma_{f}, \Sigma_{a}$, and their differences are edited. In addition, the change in $k_{\text {arr }}$ produced by $100 \%$ changes in cross section are calculated. Also, the effect of uncertainties in cross section are generated.

\subsection{The Uncommon Reactor Core Neutronics Problem.}

For stability studies, the dominant higher harmonic solution is needed. A procedure has been implemented in VENTURE to remove the fundamental contribution to the iterated solution after each outer iteration, leaving the dominant higher harmonic. This can be done for both forward and adjoint distributions. See reference [7] for additional details.

\subsection{Space-Energy Rebalance.}

Space-energy rebalance has been incorporated as an option for accelerating outer iteration convergence. It can be applied to one dimensional slab $(X)$, cylindrical $(R)$, or spherical $(R)$ geometry; two dimensional $X-Y$ or cylindrical $R-Z$ geometry; and three dimensional $X-Y-Z$ geometry. Rebalance cannot be applied to problems with internal black absorbers, or zone dependent fission spectra. 
Problems applying rebalance must be run in the "space stored" mode. Additional information on rebalance is given in reference [7].

\subsection{Adjustable Diffusion Coefficients.}

The diffusion coefficients can be adjusted in all zones as follows:

$$
D^{\prime}{ }_{k, 2}=\alpha_{1}+\alpha_{2} D_{k, 2}
$$

where $\alpha_{1}$ and $\alpha_{2}$ are input values, and $D_{k, z}$ is the calculated diffusion coefficient for group $K$ and zone $z$. This may be applied, e.g., if data is available on the increase in diffusion coefficient produced by heterogeneity.

\section{16 Equilibrium Xenon.}

Equilibrium Xenon concentration has been programmed into VENTURE, and may be used on option. The effects of equilibrium Xenon can then be evaluated without the need to use the small exposure time steps required to build xenon to its equilibrium value. This saves computer time and money. Reference [7] has additional information associated with equilibrium Xenon. 


\subsection{Temperature correlation.}

VENTURE and EXPOSURE include a temperature correlation for microscopic cross sections, so that temperature effects on reactivity can be evaluated. This requires two sets of microscopic cross sections at each of two reference temperatures. The correlation is as follows:

$$
\sigma(T)=\sigma\left(T_{1}\right)+\frac{\tan ^{-1}\left[\alpha\left(T-T_{1}\right) /\left(T_{2}-T_{1}\right)\right]}{\tan ^{-1}(\alpha)}\left[\sigma\left(T_{2}\right)-\sigma\left(T_{1}\right)\right]
$$

where $\alpha$ and the reference temperatures $T_{1}$ and $T_{2}$ must be given.

\section{EXPOSURE Code Module.}

The code module for exposure calculations is the BURNER code [8]. Input for the EXPOSURE module is accomplished by generating the EXPINS record on the CONTRL file, and the standard interface file EXPOSE generated by the Input Processor. The EXPINS record and the Standard Interface File EXPOSE are given in the SIF Handbook.

Three techniques are used to solve the burnup equations:

the matrix exponential method, the average generation rate method, and the explicit chain equation method. The methods differ by the numerical approximation techniques used to solve the coupled burnup equations. The average generation rate method uses the average precursor concentration over the time step in the precursor generation or production term. The matrix exponential method arises from expanding the exponentials in the solutions of the first order differential equations associated with burnup. The expansion order is carried out to the number of isotopes in the chain, in order to 
account for all the nuclide couplings in the chain. The explicit chain equation method directly evaluates the solutions of the burnup equations for simple chain coupling, without making numerical approximations.

The matrix exponential method is recommended for complicated couplings in the nuclide chain, while the average generation method is recommended for simple chains. The full matrix exponential method requires about three or more times the computation when compared to the average generation method. The explicit chain method requires the most computational effort.

The BURNER code uses zone dependent fluxes and cross sections, so burnup as a function of core position can be evaluated.

A flow diagram for the BURNER code is shown in Figure 6 . The subroutine listing for the code is given in Appendix III. The standard interface files associated with BURNER are shown in Figure 7. The primary zone exposure calculations require the availability of the following files: CONTRL; NDXSRF; GRUPXS; EXPOSE; RZFLUX; and ZNATDN . 

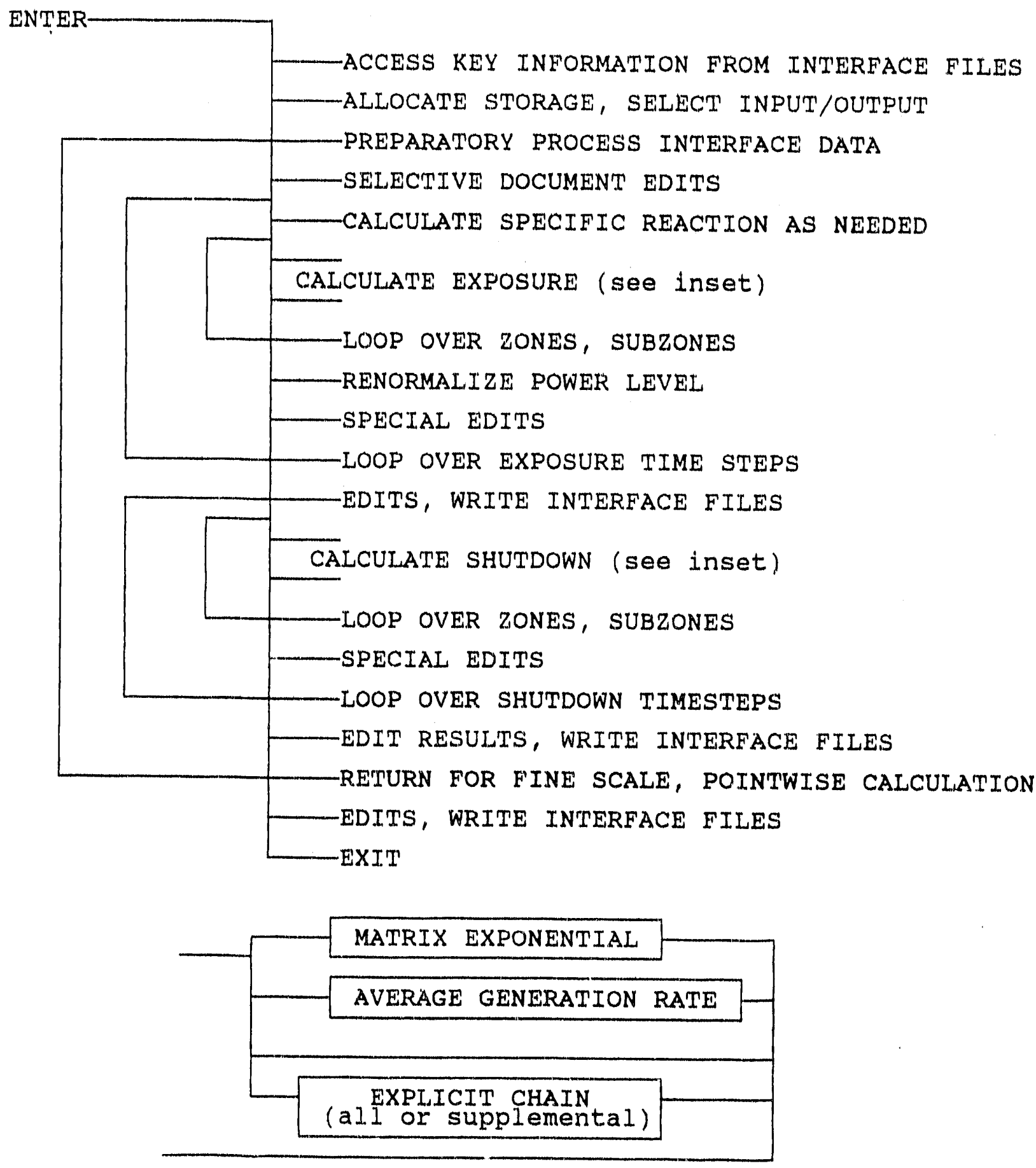

INSET

Fiqure 6. User Flow Diagram of BURNER Module 


\begin{tabular}{|c|c|c|}
\hline CONTRL & (read only) & $\begin{array}{l}\text { Instruction records EXPINS, DVRINS, } \\
\text { and PROINS }\end{array}$ \\
\hline NDXSRF & (read only) & $\begin{array}{l}\text { Nuclide referencing data and } \\
\text { nucilide concentration assignment } \\
\text { data }\end{array}$ \\
\hline GRUPXS & (read only) & $\begin{array}{l}\text { Microscopic cross section data-group } \\
\text { ordered }\end{array}$ \\
\hline EXPOSE & (read only) & Basic exposure data \\
\hline RZFLUX & (read only) & $\begin{array}{l}\text { Zone average flux also flux values } \\
\text { at selected points for a geometry } \\
\text { independent calculation } \\
\text { modified) }\end{array}$ \\
\hline ZNATDN & (read/write) & $\begin{array}{l}\text { Nuclide concentrations (zone and } \\
\text { subzone) }\end{array}$ \\
\hline PTATDN & (read/write) & $\begin{array}{l}\text { Nuclide concentrations (at selected } \\
\text { points) }\end{array}$ \\
\hline EXPOHT & ( read/write) & $\begin{array}{l}\text { Continuously updated integrals of } \\
\text { exposure conditions }\end{array}$ \\
\hline ZNTEMP & (read only) & Temperature data (zone and subzone) \\
\hline QNATDN & (write only) & $\begin{array}{l}\text { Nuclide concentrations leaving the } \\
\text { zones and subzones for the } \\
\text { continuous fueling model (same form } \\
\text { as ZNATDN) }\end{array}$ \\
\hline ZNPOWD & (write only) & $\begin{array}{l}\text { Power density data (zone } \\
\text { subzone) }\end{array}$ \\
\hline GEODST & (read only) & $\begin{array}{l}\text { Zone class data - also complete } \\
\text { geometry processing for a geometry } \\
\text { dependent calculation at selected } \\
\text { points }\end{array}$ \\
\hline RTFLUX & (read only & $\begin{array}{l}\text { Regular total flux - for a geometry } \\
\text { dependent calculation at selected } \\
\text { polnts }\end{array}$ \\
\hline
\end{tabular}

Figure 7. Interface Files Required by BURNER code (from ref. 8 ) 


\section{PARI II. DESCRIPIION OF INPU'I FOR VENIUURELPC}

\section{Input structure.}

The input consists of two main sections, 1.e, the control Module section and the Input processor section. The input blocks associated with each input section begins with a header card, which contains the name of the input section, and terminates with an END card. An example of the input structure is shown in Figure 8 . The first input section is always associated with the control Modile, which must be called first by the Driver to initialize the catalog file and the interface file CONTRL. The CONTRL file is referenced by all the modules for control information. The first card of the Control Module data contains an equal sign followed by the name of the Control Module, in this case "=CONTROL1", since CONTROLl is the present name assigned to the Control Module. The Control Module input is formatted, so care must be used in plaving the input data. The next input section is that of the Input Processor. The Input Processor will write standard interface files from free format card image or ASCII files written to comply with the standard CCCC file structure. A "STOP" card exists before the "END" card of the Input Processor. 
$=$ CONTROL 1

CONTROL MODULE DATA

END

INPUT PROCESSOR

INPUT PROCESSOR DATA

STOP

END

Figure 8. Example of Input Structure 


\section{Control Module Input.}

The user input instructions for the initial block of

data on the input file associated with the Control Module is shown In Figure 9. The name of the present version of the control module as developed at Los Alamos [4] is "CON'TROLI" and must be on card 1. following an equal sign. This input is automatically inserted by the interactive input processor, VIP, supplied with the code, and is therefore not required when the interactive input processor is utilized to generate an input file.

\subsubsection{Memory Allocation}

After the title card, the first record on the third card (or record) is the memory allocation for the data of the problem. The maximum data memory that can be accommodated for the PC version of VENTURE is 36000 words (or 144000 bytes), and this is the default value used in VIP for running the code. Smalder memory allocations can be used, but not higher, since, otherwise, the $640 \mathrm{~K}$ memory limit of DOS would be exceeded. IT IS ADVANTAGEOUS TO USE THE MAXIMUM MEMORY ALLOWABLE, since then if the problem dimensions permit, flux files used for iteration will be written as arrays in core. In addition, if there is still sufficient memory, source and other data files will be contained in core. The use of core for data storage and retrleval, significantly speeds the iteration process, as compared to disk storage and retrieval. There are times, however, when reducing the data storage allocation will help 
run a problem that may not run with tha maxtmum data storage. This is a result of the dependence of the data handing mode on the storage allocation. The data handing mode determines whether data is stored in memory or on disk, and, therefore, changes with the data memory allocation. Some problems may not run with the data handling mode associated with the maximum storage allocation. As an example, direct access file records may be larger than the Lahey compiler allows (i.e., 32 kilobytes) with the data handing mode associated with the maximum storage allocation, but these record lengths would be less than the maximum with a data handing mode associated with a smaller storage allocation. Thus, if a problem doesn't run with the maximum storage allocation, adjusting the allocation to a lower value which changes the data handing mode may help.

For application to computers other than those limited by the $640 \mathrm{~K}$ DOS limit, core storage can be increased by increasing the dimension of the data container array, designated by "A", in the FORTRAN of the DRIVER module. This container array is presently dimensioned at 36000 words. For larger core computers, increasing this dimension will allow larger problems to run within core, and greatly speed convergence, of course, recompilation would be necessary to change the container array dimension.

\subsection{Using Binary Standard Interface Files as Input.}

The parameter IP7 in columns 37 to 42 on record 3 must be set greater than zero if an interface data file is to be used as input. 
In particular, if an interface data flle such as an IsoTxs or GRUPXS file is to be input, IP7 must be set to 1 or higher. This option would be used, for example, if a GRUPXS file was generated in a previous run, and is to be used in the present run. The names of the interface files to be used as input are given by the parameter $H(I)$ on record 5. Each interface flle has a 6 letter name, and is stored as a double word containing 8 bytes, i.e., as $R E A L * 8$.

\subsection{Calculational Path.}

The calculational path is defined by the sequence of numbers on the next, or fourth record. This sequence is associated with the numbers assigned to the modules on Figure 1 . This data record defining the calculational path is crucial for the proper operation of the modules in the code, and must be constructed with care and a good understanding of how the modules interact with each other. Interface files must be available to the modules as required when they are called. 
10.4 Machine Dependent and Miscellaneous Data.

Data associated with processor time is not applicable to VENTURE/PC, since such data is machine dependent, and is designed for an IBM mainframe installation. Default values of zero should be used for such input, as IPS on record 3. Several data locations have been reserved by the originators of BOLD VENTURE for future use, and should be left blank or assigned a zero value. 


\begin{tabular}{|c|c|c|c|c|}
\hline $\begin{array}{l}\text { RECORD } \\
\text { JUMBER }\end{array}$ & $\begin{array}{l}\text { COLUMNS } \\
\text { (FORMAT) }\end{array}$ & $\begin{array}{l}\text { REFERENCE } \\
\text { NAME }\end{array}$ & $\begin{array}{l}\text { TYPICAL } \\
\text { ENTRY }\end{array}$ & USE \\
\hline 1 & 1 & & $=$ & $\begin{array}{l}\text { PRECEDES CONTROL MODULE } \\
\text { NAME. }\end{array}$ \\
\hline 1 & $2-9$ & & CONTROL1 & CONTROL MODULE NAME \\
\hline 2 & $(12 A 6)$ & TITLE & & THE RUN TITLE CARD \\
\hline 3 & $1-6$ & IP1 & 36000 & $\begin{array}{l}\text { PRIMARY MEMORY ALLOCATION } \\
\text { FOR DATA (NOTE: } 36000 \text { CAN } \\
\text { BE USED FOR ALL PROBLEMS } \\
\text { PROVIDED } 64 \text { OK OF MEMORY IS } \\
\text { AVAILABLE.) }\end{array}$ \\
\hline 3 & $7-12$ & IP2 & 0 & RESERVED \\
\hline 3 & $13-18$ & IP3 & 0 & RESERVED \\
\hline 3 & $19-24$ & IP4 & 0 & $\mathrm{NA}$ \\
\hline 3 & $25-30$ & IP5 & 0 & NA \\
\hline 3 & $31-36$ & IPG & 0 & $\mathrm{NA}$ \\
\hline 3 & $37-42$ & IP7 & & $\begin{array}{l}\text { ADDITIONAL INPUT IS } \\
\text { INCLUDED TO PRESENT } \\
\text { INFERFACE DATA FILE } \\
\text { INIFORMATION, IF >0 }\end{array}$ \\
\hline 3 & $43-48$ & IP8 & & $\begin{array}{l}\text { A MODULAR NUMBER. DATA } \\
\text { FIILS WILL BE SAVED } \\
\text { AFTER EACH ACCESS OF } \\
\text { MODULE NUMBERED IP8 }\end{array}$ \\
\hline 3 & $49-54$ & IP9 & & RESERVED \\
\hline 3 & $55-57$ & IP10 & 0 & \\
\hline 3 & $58-60$ & IP11 & 0 & \\
\hline
\end{tabular}

FIGURE 9. USER INPUT INSTRUCTIONS TO CONTROL MODULE CONTROLI 


\begin{tabular}{|c|c|c|c|}
\hline $\begin{array}{l}\text { RECORD } \\
\text { NUMBER }\end{array}$ & $\begin{array}{l}\text { COLUMNS } \\
\text { (FORMAT) }\end{array}$ & $\begin{array}{l}\text { REFERENCE } \\
\text { NAME } \\
\end{array}$ & $\begin{array}{l}\text { TYPICAL } \\
\text { ENTRY }\end{array}$ \\
\hline 3 & $61-63$ & IP12 & $\begin{array}{c}\text { INITIALIZE INTERFACE DATA } \\
\text { FILE TABLE INITIALIZATION } \\
\text { OFTION } \\
0 \text { - USE SEEK DEFAULT } \\
\text { TABLE (SETS UP 15 } \\
\text { INCLUDING CONTRL } \\
\text { AS THE FIRST) } \\
>0- \\
\text { SET UP THIS MANY } \\
\text { FROM THE LIST OF } \\
\text { WHICH CONTRL IS THE } \\
\text { FIRST }\end{array}$ \\
\hline 3 & $64-66$ & IP13 & $\begin{array}{c}\text { OPTION ON REINITIALIZATION } \\
\text { OF INTERFACE DATA FILE } \\
\text { TABLES FOR ANY SUBSEQUENT } \\
\text { ACCESS OF THE INPUT } \\
\text { PROCESSOR AFTER THE FIRST } \\
0 \text { - NO ACTION (LEAVE AS } \\
>0 \text { - RETAIN THIS MANY } \\
\text { (PLUS CONTRL) }\end{array}$ \\
\hline 3 & $67-69$ & IP14 & $\begin{array}{l}\text { EDIT LEVEL FOR CONTROL } \\
\text { MODULE PRIMARILY FOR } \\
\text { DEBUGGING IF }>0\end{array}$ \\
\hline 3 & $70-72$ & IP15 & $\begin{array}{l}\text { FRIMARY TERMINATION } \\
\text { OPTIONS }\end{array}$ \\
\hline 4 & (24I3) & $\operatorname{IM}(I)$ & $\begin{array}{l}\text { STRING OF INTEGERS PRESENTING } \\
\text { THE CODE MODULE NUMBERS TO DEFINE } \\
\text { THE CALCULATIONAL PATH, TERMINATING } \\
\text { WITH A BLANK ENTRY. A LOOP OVER A } \\
\text { SUBSTRING OF TWO OR MORE CODE } \\
\text { MODULES IS DEFINED BY A NEGATIVE } \\
\text { NUMBER WHICH IS THE NUMBER OF } \\
\text { PREVIOUS ENTRIES INCLUDED IN THE } \\
\text { LOOP, AND THE NEXT ENTRY IS THE } \\
\text { NUMBER OF PASSES THROUGH THE LOOP. }\end{array}$ \\
\hline
\end{tabular}

FIGURE 9. USER INPUT INSTRUCTIONS TO CONTROL MODULE CONTROL1 (cont.) 
THIS IS A STRING OF INTERFACE DATA FILE NAMES. TERMINATION OF EACH SET OF NAMES IS WITH A BLANK 8 COLUMN FIELD, OR AN ENTRY "X" IN THE LAST COLUMN OF A SEPARATED 8 COLUMN FIELD. THIS PROVIDES NAMES OF FILES MADE AVAILABLE FROM A PREVIOUS RUN.' NORMAL DATA BLOCK TERMINATOR.

\footnotetext{
- These files are CONTRL(10), GRUPXS(11), GEODST(12), NDXSRF(13), ZNATDN(14)， SEARCH(15)， RSTRTR(16)， RTFLUX(17)， ATFLUX(18), RZFLUX(19)， PWDINT(20)， CXSPRR(30)， ISOTXS(31)， ISOTXS(32), FIXSRC ( 33 ). The numbers in parenthesis are the logical unit numbers assigried to the files. The two IsOTXS files are required for the application of temperature effects.

- IP12 should be 1. Assignment of unit numbers is in increasing order beginning with unit 11 .
}

FIGURE 9. USER INPUT INSTRUCTIONS TO CONTROL MODULE CONTROL1 (cont.) 
10.5 Example of Input for Control Module.

An example of input for the Control Module is shown in Figure 10. The memory allocated for data in this problem is 15000 words. The "1" on card 3 in column 63 indicates that only one initial entry will be made on the catalog file, that entry associated with the file CONTRL, which must always be available. The sequence of numbers on card 4 indicate the order of the modules to be accessed. The numbers are associated with the module number assignments on Figure 1. For this problem, the Input processor, designated number 1 , will be accessed first. The VENTURE code is labeled number 7 , is then called. The Input processor must generate all of the standard interface files required by the VENTURE neutronics module. The final "O" on card 4 indicates that no additional modules will be called. 
$=$ CONTROLL

TWO DIMENSIONAL, NON SEPARABLE WATER REACTOR PROBLEM

$\begin{array}{rrllllllllllllll}15000 & 0 & 0 & 0 & 0 & 0 & 0 & 0 & 0 & 0 & 0 & 1 & 0 & 0 & 0 \\ 1 & 7 & 0 & & & & & & & & & & \end{array}$

Figure 10. Example of Input to Control Module 


\section{Input for Input Processor.}

After the Control Module input is processed, additional input must be available for the Input Processor. The primary function of the Input Processor is to create interface files entirely from card input. The card input follows a structure similar to the structure associated with the interface files themselves, and uses free format. Blanks are recommended between data entries, but other than that the data can reside anywhere on a record or card. See the Standard Interface File Handbook for details associated with using the Input Processor to generate input data.

\section{Standard Interface Files Required by Modules.}

The standard interface files required by the various modules are shown in Figure 11. Figure 11 is an extremely important figure for the proper understanding of input to VENTURE/PC. It shows the necessary control records on the file CONTRL, and indicates which standard interface files are required to run the various modules, and which files may be written by the various modules. Thus, this figure contains invaluable information associated with setting up a calculational pathway. Figure 11 should be referred to when determining VENTURE/PC input.

The first standard Interface File produced by the Input Processor must be the CONTRL file. The Control Module requires the PROINS and DVRINS recoris on the CONTRL file in that order, and these records must be the first records written on the CONTRL File. Refer to the Standard Interface File Handbook for details of the CONTRL file and the records for this file. The PROINS and DVRINS 
records are global in nature, and are required for all runs with VENTURE/PC. Additional records which are problem dependent must be placed on the CONTRL file. If the cross section procesor is required, the XCPINS record must be written on the CONTRL File. The DTNINS record is required to run the VENTURE neutronics module, so would be required for all neutronics problems. If an exposure or burnup problem is to be run, the EXPINS record is required for the BURNER module. After the PROINS and DVRINS records, the other records can appear in any order on the CONTRL file.

Additional standard Interface files are required by the cross Section Processor, VENTURE neutronics module, and the Exposure Module. If the cross section Processor reads CITATION microscopic cross sections, or updates existing ISOTXS files, or merges Isorxs files, or is used to create mixtures, the CXSPRR standard Interface File (SIF) is required (see Figure 1). If, on the other hand, the cross section processor is used only to edit an existing Isorxs file, or convert an existing ISOTXS file to a GRUPXS file, or edit a GRUPXS file, the CXSPRR SIF is not necessary.

In addition to the control information given on the DTNINS record for VENTURE, other important information must be made available to run a multigroup diffusion code like VENTURE. AII cross sections must be in group ordered form, so a GRUPXS file is required. The geometry must be specified, the mesh spacing set up, and the boundary conditions must be given. Thus, a GEODST SIF is necessary. Cross sections must be identified and assigned to mixtures, and mixtures must be asigned to zones. This is accomplished through the NDXSRF SIF. In addition, the atomic 
densities of the isotopes in mixtures assigned to zones must be given. Thus a ZNATDN SIF is required for VENTURE. The manner in which number densities of isotopes are calculated for VENTURE is discussed in section VII of the SIF Handbook.

If a burnup problem is run, in additition to the EXPINS record on the CONTRL file, the EXPOSE SIF must be made available to the BURNER module. This is in addition to other SIF's produced by VENTURE, which is run pritor to BURNER. 


\begin{tabular}{|c|c|c|c|c|c|c|}
\hline Module & No. & $\begin{array}{l}\text { Name of } \\
\text { Record in } \\
\text { File CONTRI }\end{array}$ & $\begin{array}{l}\text { Required } \\
\text { L }\end{array}$ & $\begin{array}{l}\text { Required } \\
\text { on } \\
\text { option }\end{array}$ & $\begin{array}{l}\text { Written } \\
\text { on } \\
\text { option }\end{array}$ & Ref. \\
\hline CONTROL & & $\begin{array}{l}\text { PROINS } \\
\text { DVRINS }\end{array}$ & & (any) & (any) & 1 \\
\hline $\begin{array}{l}\text { INPUT } \\
\text { PROCESSOR }\end{array}$ & 1 & & & (any) & (any) & 1,8 \\
\hline $\begin{array}{l}\text { CROSS } \\
\text { SECTION } \\
\text { PROCESSOR }\end{array}$ & 6 & XCPINS & ISOTXS & $\begin{array}{l}\text { GRUPXS } \\
\text { CXSPRR }\end{array}$ & $\begin{array}{l}\text { GRUPXS } \\
\text { ISOTXS }\end{array}$ & 2 \\
\hline $\begin{array}{l}\text { VENTURE } \\
\text { NEUTRONICS }\end{array}$ & 7 & D'TNINS & $\begin{array}{l}\text { GEODST } \\
\text { NDXSRF } \\
\text { ZNATDN } \\
\text { GRUPXS }\end{array}$ & $\begin{array}{l}\text { RTFLUX } \\
\text { ATFLUX } \\
\text { RZFLUX } \\
\text { FIXSRC } \\
\text { RSTRTR } \\
\text { SEARCH } \\
\text { ZNTEMP }\end{array}$ & $\begin{array}{l}\text { RTFLUX } \\
\text { ATFLUX } \\
\text { RZFLUX } \\
\text { FIXSRC } \\
\text { RSTRTR } \\
\text { PWDINT } \\
\text { PERTUB } \\
\text { FISSOR } \\
\text { ZNPOWD } \\
\text { GEODST }\end{array}$ & 2 \\
\hline EXPOSURE & 13 & EXPINS & $\begin{array}{l}\text { EXPOSE } \\
\text { NDXSRF } \\
\text { ZNATDN } \\
\text { GRUPXS } \\
\text { RZELUX }\end{array}$ & $\begin{array}{l}\text { PTATDN } \\
\text { ZNTEMP } \\
\text { GEODST } \\
\text { TRIGOM } \\
\text { EXPOHT } \\
\text { CFHIST } \\
\text { RTFLUX }\end{array}$ & $\begin{array}{l}\text { PTATDN } \\
\text { QNATDN } \\
\text { ZNATDN } \\
\text { ZNPOWD } \\
\text { EXPOHT } \\
\text { CFHIST }^{a}\end{array}$ & \\
\hline
\end{tabular}

May be created if it does not exist Will be used if it exists

Figure 11. Module Control Records and Interface Files (From ref. 1) 


\section{Some Examples of Input structure.}

Examples of input structure, including the structure for the sample problems [9], will be given in a format which will provide the calculational path given in the Control Module input, and the Standard Interface files and control records generated by the Input processor. The details of the files can be examined by viewing the sample problem input provided with the code package. From the point of view of learning the input, however, it is best to glve and explain the basic structure without the file details.

13.1 NEW2DXY.INP - The input structure for the revised two dimensional $X-Y$ problem is shown in Figure 12. The Control Module input indicates that the Input Processor is to be called first, followed by the VENTURE neutronics module. This is indicated by the calling sequence 170 in the control Module data, where the "o" indicates the end of the problem. These numbers correspond with the module numbers given on Figure 1. The Input Processor must generate all the files required by the VENTURE neutronics module for this problem. The control records on the Standard Interface File CONTRL are generated first. All of these records are considered to be 1D Records. The PROINS record is always given first, and always followed by the DVRINS record. The DTNINS record provides the control information for the VENTURE neutronics module and follows the other two records which are used for global information. The CONTRL file always ends with a blank record designated by 6 blanks between asterisks. VENTURE needs the following additional SIF's to proceed with the calculation: GRUPXS for cross sections; GEODST for geometry specifications; NDXSRF for cross section referencing; and 
ZNATDN for zone atomio densities. These are alid deve? oped through the Input processor. The Input processor always conoludes data input with a STOP card followed by an END card. 
$=$ CONTROLI

TWO DIMENSIONAI, NON SEPARABLE WATER REACTOR PROBLEM

36000

170

END

INPUT PROCESSOR

OV CONTRL

ID PROINS

ID DVRINS

1D DININS

1D* * $* 0.0100 \mathrm{R}$ O 100R

OV GRUPXS

OV GEODST

OV NDXSRF

OV ZNATDN

STOP

END

Figure 12. Input Structure for Two Dimensional $X-Y$ Problem. 
13.2 NEWBWR, INP - The input structure for the revised BWR assembly $X-Y$ analyses is shown in Figure 13. This data combines the $12 \times 12$ and $24 \times 24$ cases given separately in previous versions of VENTURE/PC. The Control Module indicates the following sequence for calling modules: 167170 . Thus, the Input processor (1) is called first, followed by the cross section processor (6), and the VENTURE neutronics module (7). These are followed by the Input Processor (1.) and VENTURE module (7) to run the second problem. CITATION cross sections were used for this problem. The CITATION cross sections must be processed by the separate DCMACR code to convert macroscopio cross sections to microscopic and wrtte them on unit 8. The DCMACR processing must be done on the same subdirectory as the VENTURE code.

The control records are generated on the CONTRL file by the Input processor. These include, as always, the global records PROINS and DVRINS in that order. The XCPINS control record is required for this problem, since the cross section processor is used to process the CITATION cross sections and convert them to GRUPXS form. Then, of course, the DTNINS file is required to run the VENTURE module.

The CXSPRR standard interface file is also necessary for this problem, since CITATION cross sections are processed.

In addition to cross sections, VENTURE also needs the GEODST, NDXSRF and ZNATDN files.

The same cross sections are used for the second problem, but different GEODST, NDXSRF and ZNATDN files are required. Thus, the Input Processor is rerun to generate the new files. 


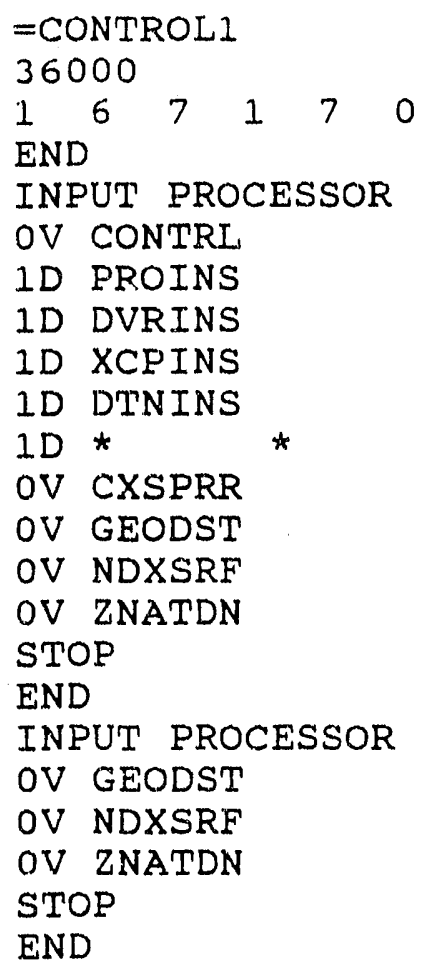

Figure 13. Input Structure for BWR Assembly Sample Problems. 
13.3 Three Theta-R cases - The input for three theta-R cases run in succession is shown in Figure 14. The calling sequence is 1671 7170 , indicating that the Input processor is called first, followed by the cross section Processor and the VENTURE neutronics module, which completes the first problem. The remaining two problems require the Input processor and VENTURE module in that order called twice, once for each problem.

This problem also uses CITATION cross sections. The Input Processor first writes the necessary records on the CONTRL file. These include: PROINS, DVRINS, XCPINS and DTNINS, as in the previous problem. The CXSPRR Standard Interface File must be written for the cross section processor to convert CITATION cross sections for use by VENTURE. The GEODST, NDXSRF and ZNATDN files must be written for VENTURE. The Input processor is called twice more, in between calls to VENTURE, to write new GEODST, NDXSRF and ZNATDN files to run the remaining two problems. 


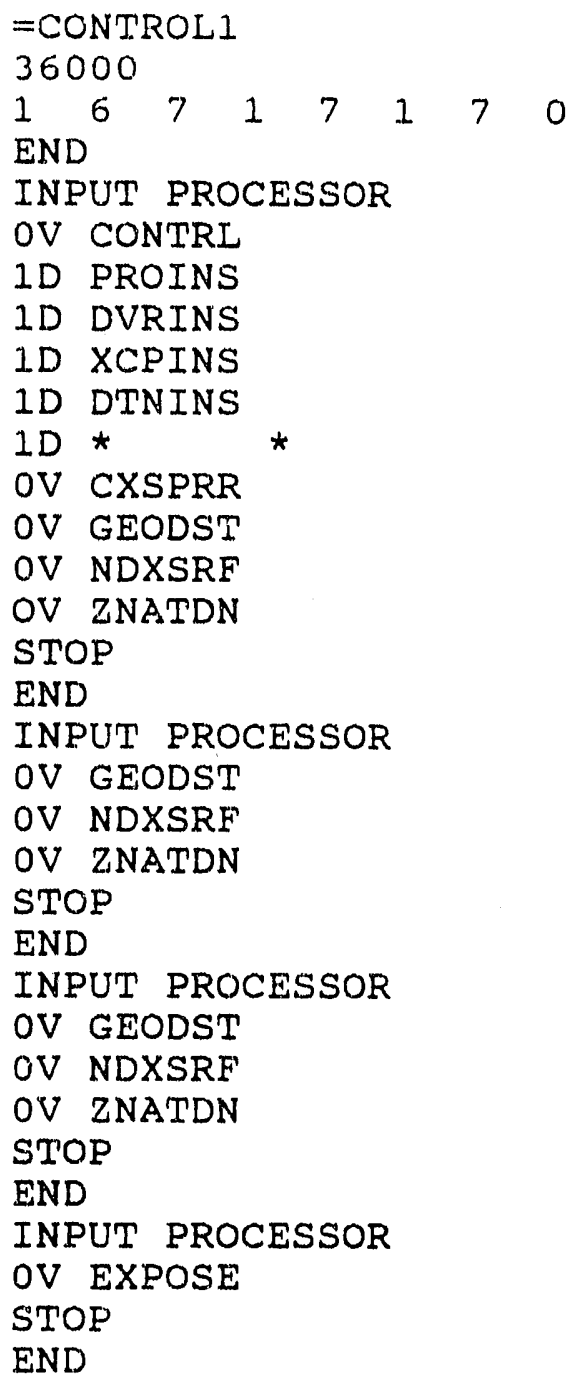

Figure 14. Input Structure for Three Theta-R Problems. 
13.4 Exposure Problem. - An input structure for an exposure problem is shown in Figure 15. In this problem the calling sequence is:

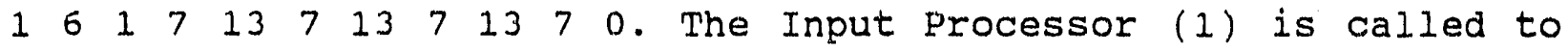
write the CONTRL file, followed by the cross Section Processor (6) required to convert an ISOTXS file to a GRUPXS file, followed by the Input processor again to write the EXPOSE Standard Interface File required by the BURNER module, followed by the VENTURE (7) neutronics module which calculates the flux for the BURNER module (13) and the initial burnup step, afterwhich The VENTURE and BURNER modules are alternated for the number of burnup steps desired ( 3 in the example shown). The Input Processor first writes the PROINS and DVRINS control records which are always required. It then writes the XCPINS record for the cross section Processor, the DTNINS record for the VENTURE module, and the EXPINS record for the BURNER module. It also writes the ISOTXS file which is converted by the Cross Section Processor to a GRUPXS file, and the three additional standard interface files required by VENTURE, i.e., the GEODST, NDXSRF, and the ZNATDN files. In addition, it is called again to write the EXPOSE file required to run the BURNER module. 
$=$ CONTROLL

REFERENCE CALCULATION FOR DPT SAMPLE PROBLEMS 36000

$\begin{array}{lllllllllll}1 & 6 & 1 & 7 & 13 & 7 & 13 & 7 & 13 & 7 & 0\end{array}$

END

INPUT PROCESSOR

OV CONTROL

ID PROINS

1D DVRINS

1D XCPINS

1D DTNINS

ID EXPINS

$1 D *$

OV ISOTXS

OV GEODST

OV NDXSRF

OV ZNATDN

STOP

END

INPUT PROCESSOR

OV EXPOSE

STOP

END

Figure 15. Input Structure for an Exposure Problem. 


\subsection{Using Standard Interface Files on Input.}

If standard Interface files are available on the VENTURE subdirectory, they can be used directly without using the Input Processor to generate them. This is accomplished through the Control Module, as previously explained (Section 10.2). An example for running a VENTURE problem with all of the necessary SIF's available, i.e., GRUPXS, GEODST, NDXSRF and ZNATDN is shown in Figure 16. 
$=$ CONTROL1

EXAMPLE OF VENTURE RUN WITH NECESSARY INTERFACE FILES AVAILABLE 36000 1

70

GRUPXS GEODST NDXSRF ZNATDN $\mathrm{X}$

END

Figure 16. Example of Input with Standard Interface Files 


\section{Relocating Fuel Bundles.}

In version 2 of VENTURE/PC, the special processor DENMAN was used to change mixtures assigned to zones or subzones, and to change nuclide concentrations, which in effect could be used to simulate core bundle reshuffing. In version 3 , however, all special processors have been removed, including DENMAN. Fuel reshuffing can be simulated, however, by using the Input Processor to overlay and change the NDXSRF and ZNATDN standard interface files.

\section{Data Transfer, File Management and Input-output.}

Data transfer and file management are accomplished with standardized routines which are used by all code modules and subroutines.

\subsection{Standardized Routines.}

The standardized subroutines and their functions are:

REED - Transfers data from disk to memory.

RITE - Transfers data from memory to disk.

DOPC - Basic input-output management. Opens and closes files, and differentiates between sequential and direct access files. Only scratch files can use direct access. Direct Access Files cannot be named with the Lahey compiler used.

SEEK - Maintains file catalog, keeping track of file name, unit number, and version number. Subroutines often call SEEK to establish the unit number for a given file. 


\subsection{Input and output Files.}

The input to run a given problem must be on a file named VENTURE.INP, which is assigned unit number one. The Driver overwrites the input for the various modules, i.e., the input between the header card and END card, on unit 5, and all data is read from this unit. This file on unit 5 has been named VENTURE.TMP. All output is written on unit 6 , in the file labeled VENTURE.OUT, so the output can be read by editing this file. The output is quite extensive, so the VENTURE.OUT file should be edited prior to printing. A condensed output file is written on unit 99 , which provides file management and data access information. This file has been labeled CONDENSE.OUT.

\subsection{Saving of Standard Interface Files.}

The standard interface files generated during a run are saved with their name, so they may be used in subsequent runs. These include, with their usual unit number assignments:

$$
\begin{aligned}
& \text { CONTRL - Unit } 10 \\
& \text { GRUPXS - Unit } 11 \\
& \text { GEODST - Unit } 12 \\
& \text { NDXSRF - Unit } 13 \\
& \text { ZNATDN - Unit } 14 \\
& \text { SEARCH - Unit } 15 \\
& \text { RSTRTR - Unit } 16 \\
& \text { RTFLUX - Unit } 17 \\
& \text { ATFLUX - Unit } 18 \\
& \text { RZFLUX - Unit } 19 \\
& \text { PWDINT - Unit } 20
\end{aligned}
$$




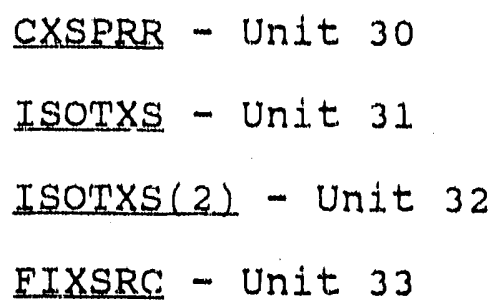

\subsection{Scratch and Direct Access Files.}

other files which are generated during a run are named VENTNO, where the No is the unit number of the file. Thus, VENT36 is a file generated during the run on unit 36 . These files are deleted at the end of a successful run, but will appear on the disk in the case of an aborted run. Direct access files are not saved.

The general assignment of files is as follows:

Unit 09 - Catalog File

Unit 10 - CONTRL file

Units 21-29 and 40-69 - Scratch files

Units 10-20 and 30-39 and $70-97$ - Standard

Interface Files

Unit 98 - Control module instructions

15.5 Saving of standard Interface File in Text Format.

If the selection was made to save results as formatted data (see parameter IX(60) of DTNINS input), the results will be on a file named STFILE.TXT, for standard Files in text format. 
16. Correspondence Between DVENTR and DTNINS.

The control information for the VENTURE neutronics code could be input through the special processor DVENTR in version 2 of VENTURE/PC. The same information is included in the DTNINS control record, and is input through this record in version 3 of VENTURE/PC. The correspondence between the input parameters in DVENTR and DTNINS, taken from reference [1] j.s shown in Table 16.1 . 
Table 16.1 Correspondence Between DVENTR and DTNINS Parameters

\begin{tabular}{|c|c|c|c|c|c|}
\hline $\begin{array}{c}\text { DVENTR } \\
\text { Input } \\
\text { Sed.001 } \\
\end{array}$ & $\begin{array}{l}\text { DTNINS } \\
\text { Record }\end{array}$ & $\begin{array}{l}\text { DVENTR } \\
\text { Input } \\
\text { SeC. 001. }\end{array}$ & $\begin{array}{l}\text { DTNINS } \\
\text { Record }\end{array}$ & $\begin{array}{l}\text { DVENTR } \\
\text { Input } \\
\text { Seo. } 001\end{array}$ & $\begin{array}{l}\text { DTNINS } \\
\text { Record }\end{array}$ \\
\hline RRX1. & $\mathrm{XX}(1)$ & ICX.L & $\operatorname{IX}(4)$ & IXE1 & $\operatorname{IX}(32)$ \\
\hline RRX2 & $x \times(2)$ & $\operatorname{ICX} 2$ & $\operatorname{IX}(5)$ & IXE2 & $\operatorname{IX}(33)$ \\
\hline $\mathrm{R} \times \times 3$ & $x \times(3)$ & $\operatorname{ICX} 3$ & $\operatorname{IX}(1.0)$ & IXE3 & $\operatorname{IX}(35)$ \\
\hline $\mathrm{RXX} 4$ & $x \times(4)$ & $\operatorname{ICX} 4$ & $\operatorname{IX}(6)$ & IXE 4 & $\operatorname{IX}(38)$ \\
\hline $\mathrm{R} \times \times 5$ & $X X(5)$ & ICX5 & $\operatorname{IX}(9)$ & IXE5 & $\operatorname{IX}(39)$ \\
\hline $\mathrm{R} \times \mathrm{XG}$ & $\mathrm{XX}(6)$ & $\operatorname{ICX} 6$ & $\operatorname{IX}(8)$ & IXE6 & $\operatorname{IX}(40)$ \\
\hline $\mathrm{R} \times \times 7$ & $\mathrm{XX}(14)$ & ICX7 & $\operatorname{IX}(2)$ & IXE7 & $\operatorname{IX}(41)$ \\
\hline $\mathrm{RXX8}$ & $X X(9)$ & ICX8 & $\operatorname{IX}(26)$ & IXE8 & $\operatorname{IX}(42)$ \\
\hline $\mathrm{R} \times \times 9$ & $x \times(10)$ & ICX9 & $\operatorname{IX}(23)$ & IXE9 & $\operatorname{Ix}(37)$ \\
\hline $\mathrm{R} \times \times 10$ & $\mathrm{XX}(8)$ & $\operatorname{ICX} 10$ & IX (22) & IXE1O & $\operatorname{Ix}(31)$ \\
\hline$R \times X 11$ & $\mathrm{xx}(11)$ & $I C \times 11$ & $I X(21)$ & IXE 11 & $\operatorname{IX}(29)$ \\
\hline $\mathrm{R} \times \times 12$ & $\mathrm{Xx}(12)$ & $\operatorname{ICX} 12$ & $\operatorname{IX}(20)$ & IXEL2 & $\operatorname{IX}(30)$ \\
\hline$R \times \times 13$ & $x \times(13)$ & $\operatorname{ICX} 13$ & $\operatorname{IX}(27)$ & IXE13 & $\operatorname{IX}(61)$ \\
\hline $\mathrm{R} \times \times 14$ & $x x(15)$ & $I C \times 14$ & IX(25) & IXE14 & $\operatorname{IX}(62)$ \\
\hline $\mathrm{R} \times \times 1.5$ & $\mathrm{xx}(16)$ & $I C \times 15$ & $\operatorname{IX}(24)$ & IXE15 & $\operatorname{IX}(51)$ \\
\hline $\mathrm{R} \times \mathrm{X} 16$ & $x \times(7)$ & ICX16 & $\operatorname{IX}(12)$ & IXE16 & $\tau X(58)$ \\
\hline $\mathrm{R} \times \times 127$ & & $\operatorname{ICX} 17$ & $\operatorname{IX}(17)$ & [XE17 & $\operatorname{IX}(53)$ \\
\hline \multirow[t]{7}{*}{$\mathrm{R} \times 1 \mathrm{13}$} & & $\operatorname{ICX} 18$ & $\operatorname{IX}(18)$ & IXE18 & $1 \times 54$ \\
\hline & & ICX19 & $\operatorname{IX}(19)$ & IXE19 & $\operatorname{IX}(52)$ \\
\hline & & ICX 20 & $\operatorname{IX}(16)$ & IXE20 & No \\
\hline & & $\operatorname{ICX} 21$ & $I X(13)$ & IXE21 & $\operatorname{IX}(81)$ \\
\hline & & $I C \times 22$ & $I X(1.4)$ & IXE22 & $\operatorname{Ix}(45)$ \\
\hline & & ICX23 & IX (15) & IXE23 & $\operatorname{IX}(59)$ \\
\hline & & $\operatorname{ICX} 24$ & $I X(70)$ & IXE24 & $\operatorname{IX}(60)$ \\
\hline
\end{tabular}


Table 16.1 Correspondence Between DVENTR and DTNINS Parameters (continued)

\begin{tabular}{|c|c|c|c|c|c|}
\hline $\begin{array}{c}\text { DVENTK } \\
\text { Input } \\
\text { Sec. } 002 \\
\end{array}$ & $\begin{array}{l}\text { DTNINS } \\
\text { Record }\end{array}$ & $\begin{array}{c}\text { DVENTR } \\
\text { Input. } \\
\text { Sec. } 002\end{array}$ & $\begin{array}{l}\text { DTNINS } \\
\text { Record }\end{array}$ & $\begin{array}{c}\text { DVENTR } \\
\text { Input } \\
\text { Sec. } 002 \\
\end{array}$ & $\begin{array}{l}\text { DTNINS } \\
\text { Record }\end{array}$ \\
\hline RXXN1 & $x \times(19)$ & IXCN1 & $\operatorname{IX}(11)$ & IXEN 1 & $\operatorname{IX}(46)$ \\
\hline $\mathrm{RXXN2}$ & $x x(20)$ & IXCN2 & IX (7) & IXEN 2 & $\operatorname{IX}(47)$ \\
\hline RXXN3 & $x \times(2 \pm)$ & {$[X C N 3$} & $\operatorname{IX}(73)$ & IXEN 3 & $\operatorname{IX}(48)$ \\
\hline $\mathrm{R} \times \times \mathrm{N} 4$ & $x \times(22)$ & IXCN 4 & $\operatorname{IX}(74)$ & IXEN 4 & $\operatorname{IX}(55)$ \\
\hline $\mathrm{R} \times \times N 5$ & $x \times(23)$ & IXCN5 & $\operatorname{IX}(75)$ & IXEN5 & $\operatorname{IX}(28)$ \\
\hline RXXNG & $x \times(24)$ & IXCN6 & $\operatorname{IX}(76)$ & IXENG & $\operatorname{IX}(34)$ \\
\hline RXXN7 & $x \times(25)$ & IXCN7 & $\operatorname{IX}(77)$ & IXEN 7 & $\operatorname{IX}(36)$ \\
\hline RXXN8 & $x \times(26)$ & IXCN8 & $\operatorname{IX}(78)$ & IXEN8 & $\operatorname{IX}(43)$ \\
\hline RXXN9 & $x \times(27)$ & IXCN 9 & $\operatorname{IX}(79)$ & IXEN9 & $\operatorname{IX}(44)$ \\
\hline $\mathrm{RXXN10}$ & $x \times(28)$ & IXCN 10 & $\operatorname{IX}(80)$ & IXEN10 & $\operatorname{IX}(49)$ \\
\hline $\mathrm{RXXN11}$ & $\times \times(29)$ & IXCN 11 & & IXEN11 & $\operatorname{IX}(50)$ \\
\hline \multirow[t]{13}{*}{$\mathrm{RXXN12}$} & $x \times(30)$ & IXCN12 & $\operatorname{IX}(82)$ & IXEN12 & $\operatorname{IX}(56)$ \\
\hline & & IXCN 13 & $\operatorname{IX}(83)$ & IXEN13 & $\operatorname{IX}(57)$ \\
\hline & & IXCN 14 & $\operatorname{IX}(84)$ & IXEN14 & $\operatorname{IX}(63)$ \\
\hline & & IXCN15 & $\operatorname{IX}(85)$ & IXEN15 & $\operatorname{IX}(64)$ \\
\hline & & $\operatorname{IXCN} 16$ & $\operatorname{IX}(86)$ & IXEN 16 & $\operatorname{IX}(65)$ \\
\hline & & IXCN17 & $\operatorname{IX}(87)$ & IXEN17 & $\operatorname{IX}(66)$ \\
\hline & & IXCN 18 & $\operatorname{IX}(88)$ & IXEN1 8 & $\operatorname{IX}(67)$ \\
\hline & & IXCN.19 & $\operatorname{IX}(89)$ & IXEN19 & $\operatorname{IX}(68)$ \\
\hline & & IXCN 20 & $\operatorname{IX}(90)$ & IXEN 20 & $\operatorname{IX}(69)$ \\
\hline & & IXCN 21 & & IXEN21 & \\
\hline & & IXCN 22 & & IXEN22 & \\
\hline & & $\operatorname{IXCN} 23$ & & IXEN 23 & \\
\hline & & $\operatorname{IXCN} 24$ & & IXEN 24 & \\
\hline
\end{tabular}




\section{Compiler and overlay structure for VENIURE Code.}

The VENTURE/PC code modules were obtained from the BOLD

VENTURE code system by downloading; the source files from a mainframe tape to a PC via modem. The source codes were edited, and the subroutines extracted and combined with the BRIEF PC Editor [10], and complied with the Lahey Fortran 77 complier [11].

The executable file for VENTURE/PC requires 3 milition

bytes, so cannot be run within the $640 \mathrm{~K}$ of DOS without overlay. The PHOENIX86 Plus [1.2] overlay linker was used to reduce the size of the runtime code to about 540K. This overlay linker aljows for several levels of overlay. The overlay structure is such that only subroutines which call each other, or depend on each other, are in memory simultaneously, while the others reside on disk waiting to be called. When they are called, they overlay the existing routires in memory. In this manner, large codes can be run within memory restrictions. The overlay structure for VENTURE, as taken from the PLINK86 input, is show in Figure 17. Files which are on the same Ine in this figure, are in memory simultaneously. This is the case for the DRIVER and VENTNEUT, for example, and for the subroutines VENT and IONO. The DRIVER and VENTNEUT are in the root, and are always in memory. Files which are in the same sections, but on different lines, overlay one another in memory. Thus, CONTROL1 and INPROSER do not reside in memory together, but overlay each other. Sections which are indented, reside in another level of overlay, and require their parent file in memory. Thus, in using the Input Processor, INPROSER must be in memory along with the root files DRIVER and VENTNEUT, but the files CGE, CIO, CGR etc., can overlay 
each other as they are called by INPROSER. Actually, the file names shown on the figure consist of more than one subroutine which were compiled together, and which must be in memory together since they call each other. The subroutines assigned to the various names of Figure 17 are shown in Figure 18. Figure 18 can be compared with Appendix II and III which define the subroutines for VENTURE and BURNER, respectively.

In addition to overlaying code, the PLINk86 overlay linker provides an option to overlay data segments [13]. When this option was selected, the container array for data could be increased from 16000 words to 36000 words. This is a very significant increase, and allows for much larger problems to be run. 


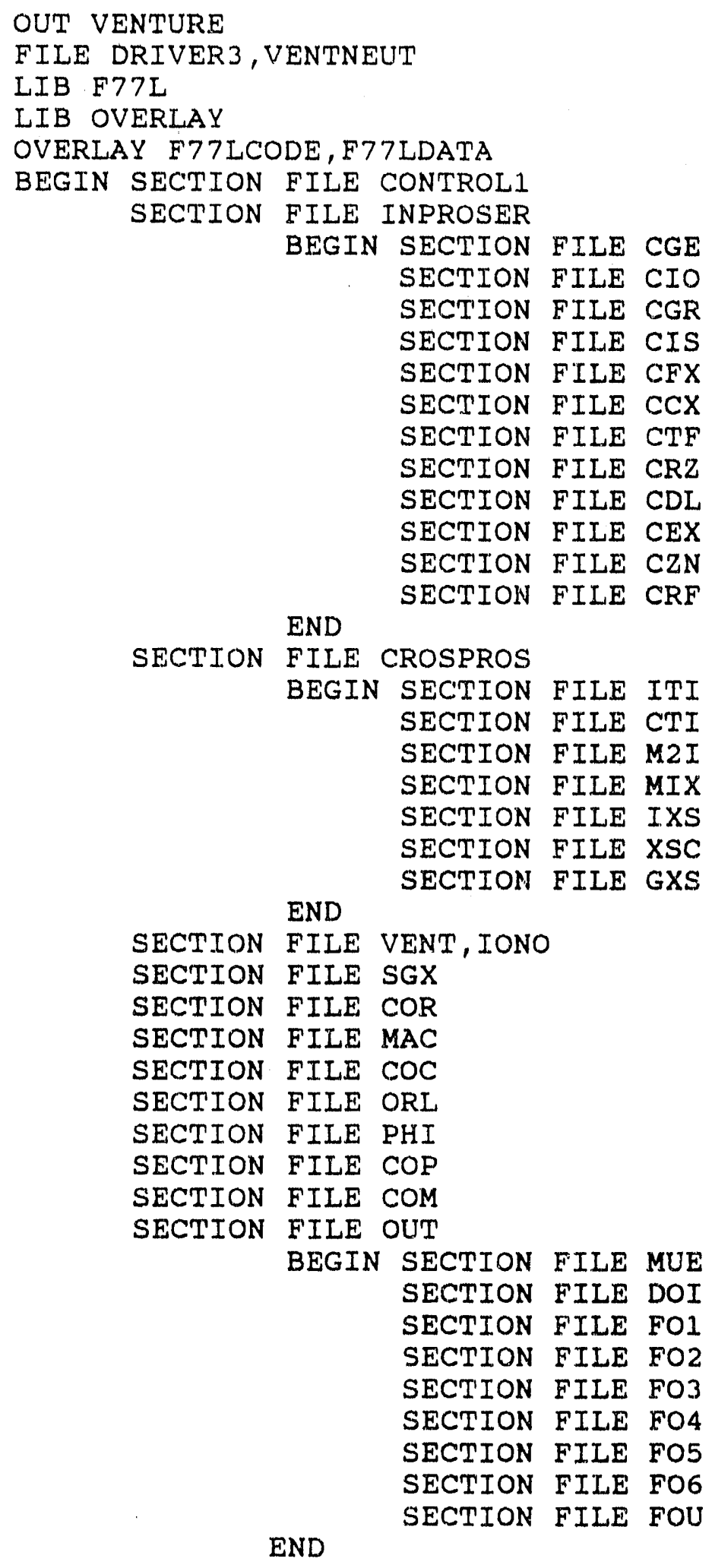

Figure 17. VENTURE overlay structure 


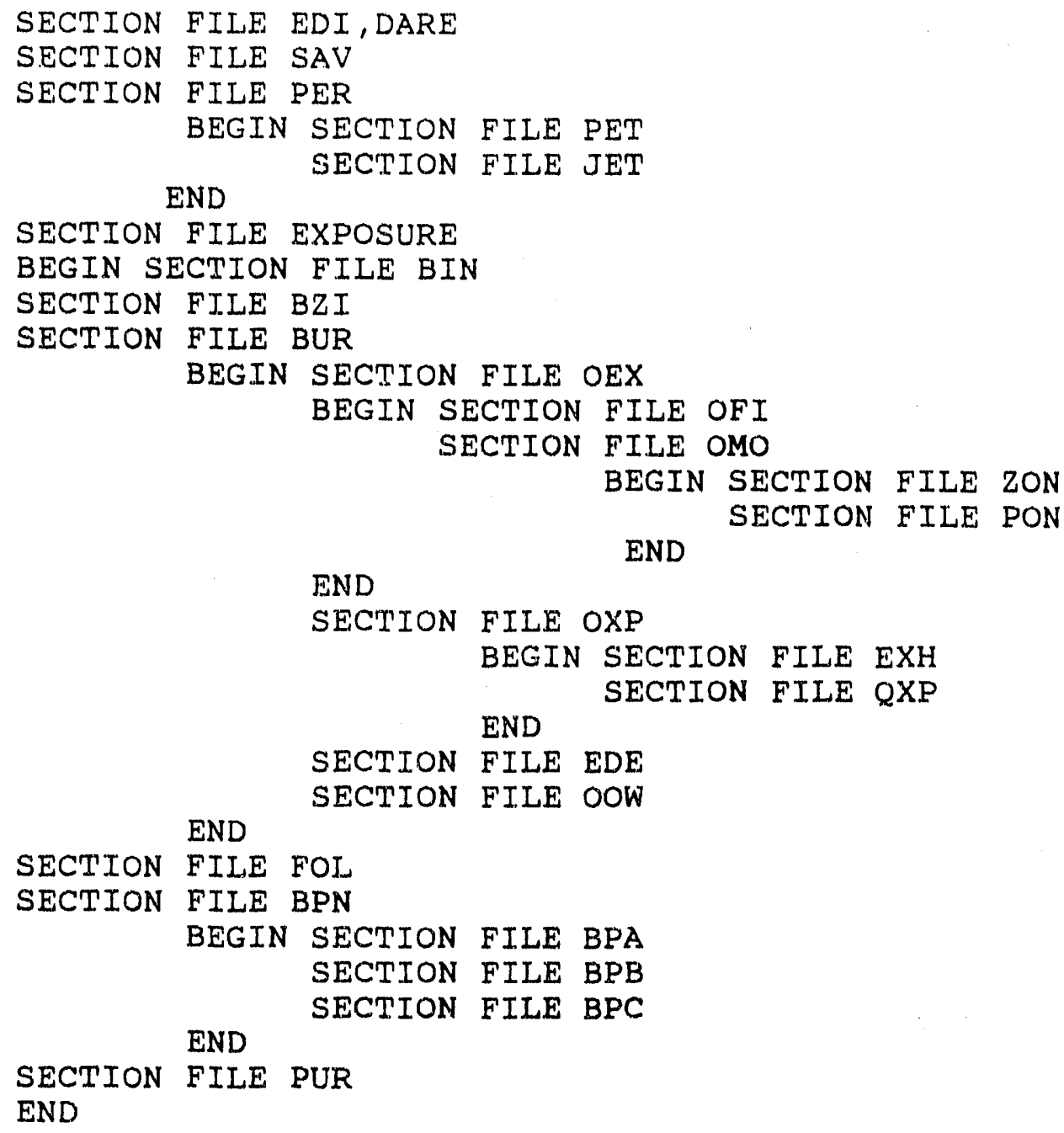

END；

Figure 17. VENTURE Overlay structure (Cont.) 


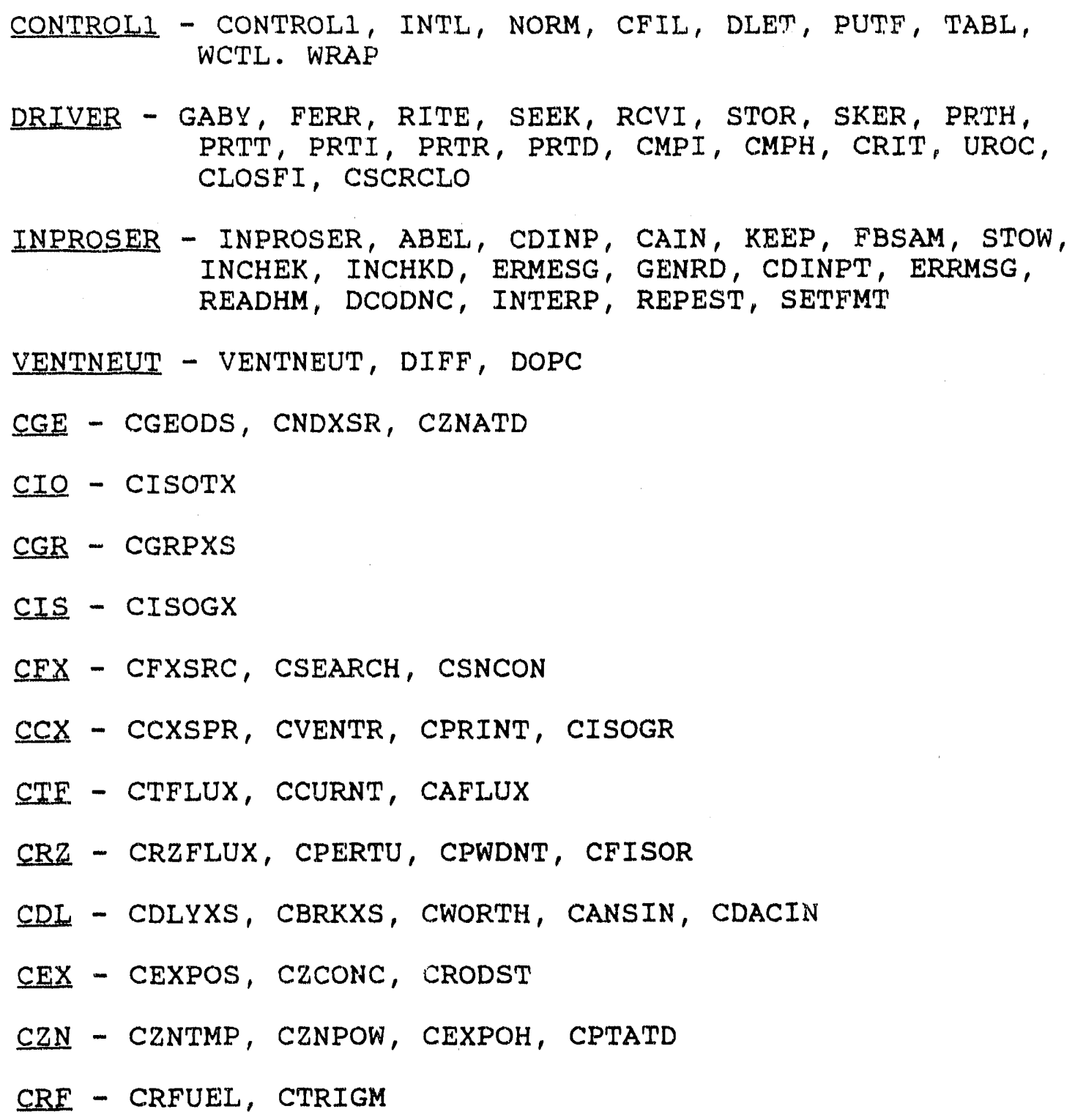

Figure 18. Subroutines in VENTURE/PC overlay structure 


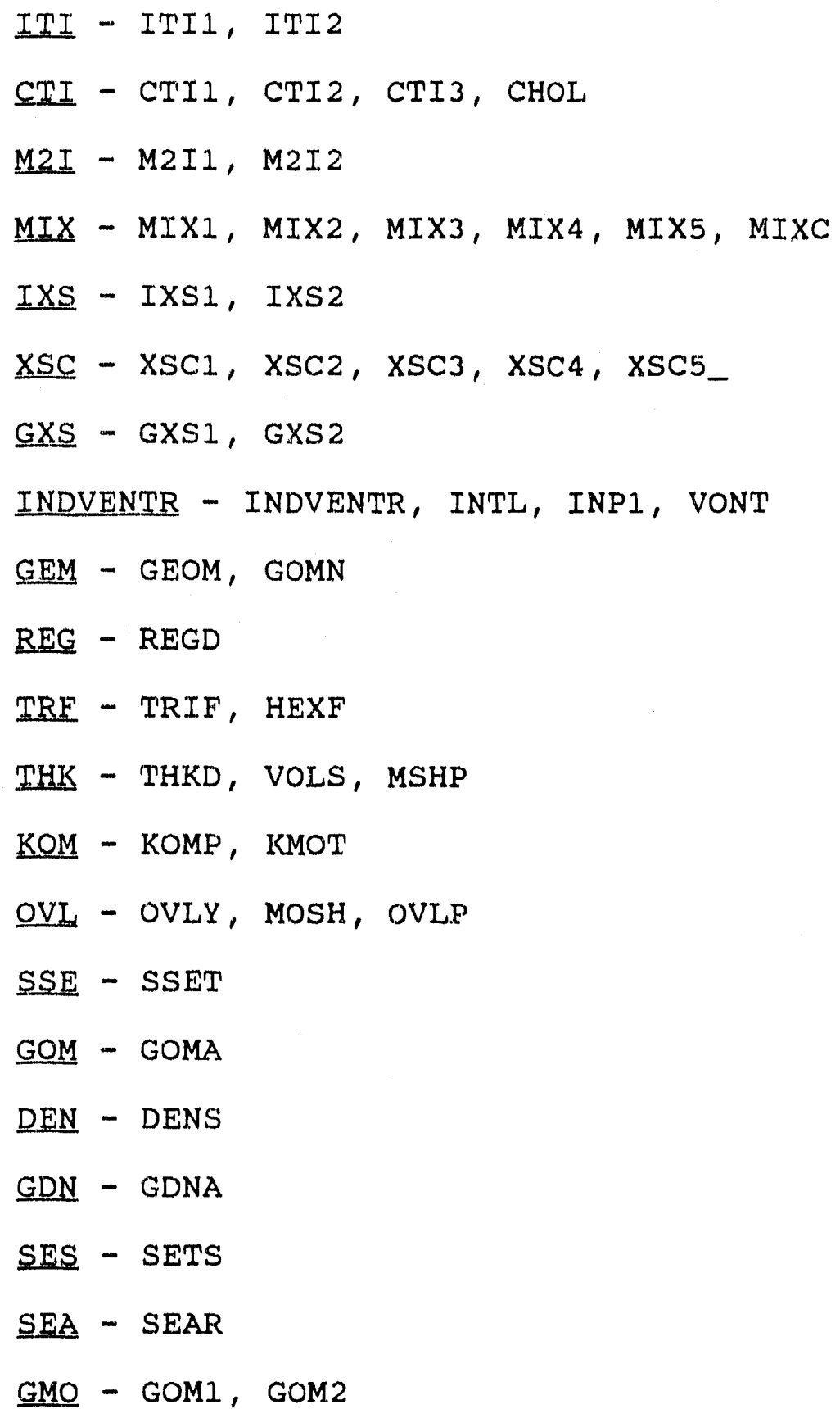


ZND ZND1, ZND2

NDR NDR1， NDR2

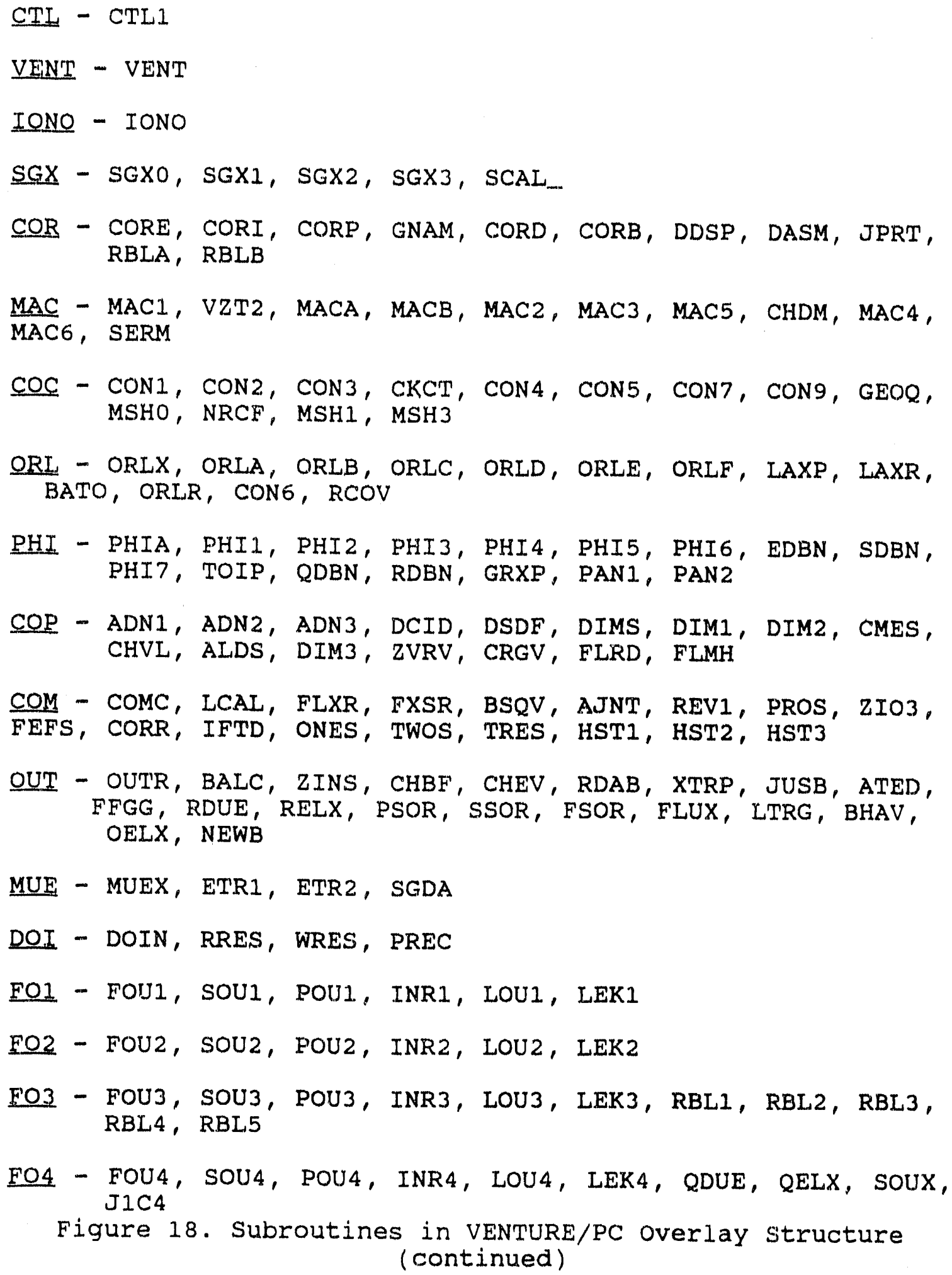


FO5 - FOU5, SOU5, POU5, INR5, LOU5, LEK5, J1C5

E06 - FOU6, SOU6, INR6, DELX

FOU - FOUX, SOUY, POUX, INRX, LOUX, LEKX, SOUZ, J1CX

SAV - SAV1, SAV2, SAV3, SAV4, SAV5, SAV6, SAV7

PER - PERO, RTUB, MRPT, QOUT, BBB1, BBB2, EASU

EDI - EDIT, POUT, NBAL, SOBL, FISS, FLXW, BSQS, PNDN, PTVL, PTZF, JINT, PND1, PND2, PND3, PND4, PND5

DARE

PET - PERT, TUFY, LIFE, DAFA, MAPS, PMAP

JET - JERT, JUFY, JIFE, JAFA, JAPS, JMAP, JGET

THE NEXT SET OF SUBROUTINES ARE ASSOCIATED WITH EXPOSURE:

BIN - BINP, GNZC, BRN7, BRN4, BGXS, BZT1, BRNF, BRNW, ZJC2, ZJCY, ZIGY, EPFD, BRNX, HQUE, SKNU

BZI - BZIN, DEEF, CMOV, BRNS, BRN3, BRNZ, BRNT, BZT2, BRNA, BRND， BRRF， PRRF

OFI - OFIX, BFIX

OEX - OEXP, POWL, ARRI, ZCRI, PARI, BRNO

BUR - BURN, BRNY, ZNAW, ZZPD, AUXE, TPNE

ZON - ZOND, ZZPF, ZONI, POWP

OMO - OMOV, BMOV

PON - PONI, PPOE, QNAW, QNAT

OXP - OXPH, CPHI, ECHK, ESET, FLUE

EXH - EXPH, REHT, CPH2, EPH2

QXP - QXPH, QPTD, QFLU, QEHT, CPH3, EPH3

EDE - EDEP, EDED, ETAB

OOW - OOWN, DOWN

Figure 18. Subroutines in VENTURE/PC overlay structure (cont.) 


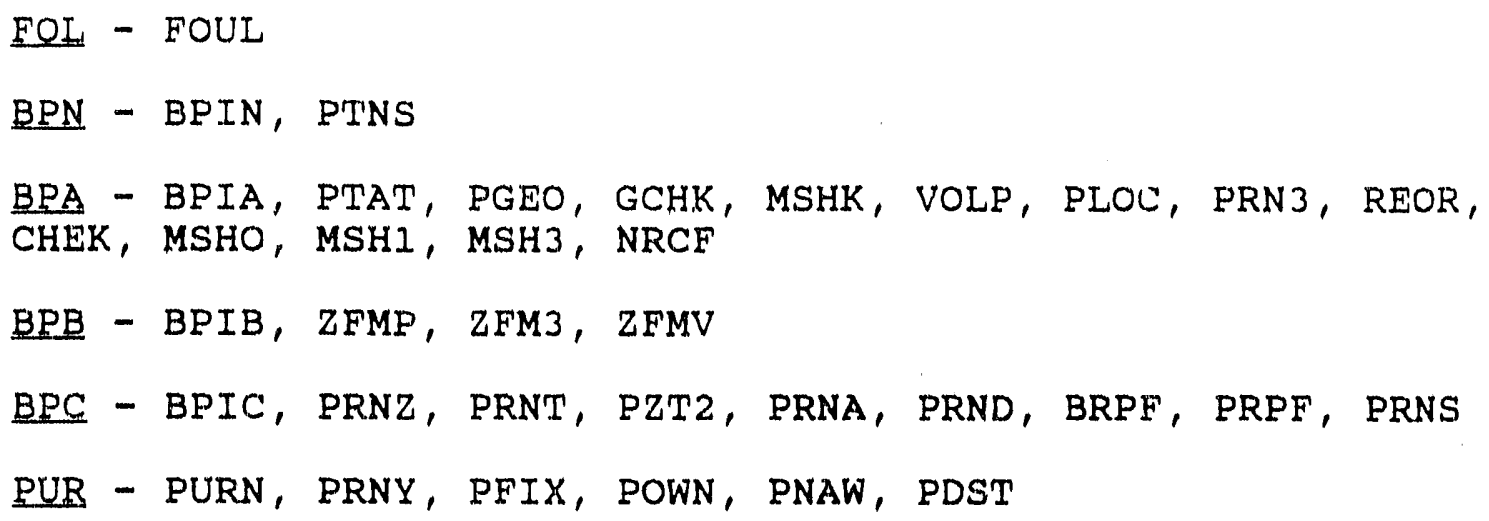

Figure 18. Subroutines in VENTURE/PC overlay structure (continued) 
18. VENTURE/PC Interactive Processor, "VIP",

An interactive input processor is included with the code. The processor, called VIP for VENTURE INTERACTIVE PROCESSOR, was written in FORTRAN and complled with the Lahey FORTRAN-77 compiler, version 2.22. The processor is rather large, utilizing about 900,000 bytes, and, therefore, required overlaying during the linking process. The overlay structure for the VIP executable program is shown in Figure 19.

The processor prompts the user for the input, and should be reasonably self explanatory. Reviews of the input are provided after each major section, at which point erroneous input can be corrected. 
OUT VIP

FILE VIP

LIB $C: \backslash$ LAHEY \F77I

LIB OVERLAYY

OVERLAY F77LCODE, F77LDATA

BEGIN SECTION FILE CONTRLU, CONTRL2

SECTION FILE GRUPXS

SECTION FILE ISOTXS

SECTION FILE GEODST

SECTION FILE NDXSRF

SECTION FIIE ZNATDN

SECTION FILE SEARCH

END ;

SECTION FILE EXPOSE

Figure 19. VIP overlay Structure 


\section{REEERENCES}

1. "BOLD VENTURE IV, A Reactor Analysis Code system, Version IV", RSIC Computer Code Collection, CCC-459, Radiation shielding Information Center, Oak Ridge National Laboratory, June, 1984. This reference provides the extensions made to the previous version of BOLD VENTURE. It also provides the updated input requirements.

2. R. Douglas O'Del1, "Standard Interface Flles and Procedures for Reactor Physics Codes, Version IV", LA-6941-MS, LOs Alamos Sclentific Laboratory, September, 1977.

An excelient description of the purpose and format of standard Interface Files and DOE code standardization.

3. Bosher, G.E., Odell, R.D., Resnik, W.M, "LASIP-III, A Generalized Processor for Standard Interface Files", LA-6280-MS, Los Alamos Scientific Laboratory, April, 1976.

A description and discussion of the Los Alamos Input Processor for converting card image format to standard Interface Files.

4. Vondy, D.R., Fowler, T.B., Cunningham, G.W., Petrie, L.M., "A Computation System for Nuclear Reactor Core Analysis", Oak Ridge National. Laboratory, ORNL-5518, April, 1.977.

A description of the system and codes used with VENTURE for nuclear reactor core analysis.

5. Vondy, D.R., Fowler, T.B., Cunningham G.W., "VENTURE: A Code Block for Solving Multigroup Neutronics problems Applying the Finite Difference Diffusion Theory Approximation to Neutron Transport, Version II", ORNL-5062/RI, Oak Ridge National Lab, Nov. 1977.

An earlier version of VENTURE, but the most definitive report on the VENTURE neutronics module, providing a detalled account of the theory and equations assocjated with the code.

6. Fowler, T.B., Vondy, D.R., Cunningham, G.W., "Nuclear Reactor Core Analysis Code: CITATION", ORNL-TM-2496, Rev. 2, July, 1969 The precursor code to VENTURE.

7. Vondy, D.R., Fowler, T.B., Cunningham, G.W., "The Bold Venture Computation System for Nuclear Reactor Core Analysis, Version III', Oak Ridge National Lab, ORNL-5711, June, 1981.

Essentially the same as reference 1 , but given as an Oak Ridge report rather than as a computer code collection.

8. Vondy, D.R. and Cunningham, G.W., "Exposure Calculational Code Module for Reactor Core Analysis: BURNER", ORNL-5180, Oak Ridge National Lab., Feb. 1979.

A description of, and the theory used, in the BURNER code module for isotope depletion and production. 
9. Vondy, D.R. and Fowler T.B., "Reference Test problems for the VENTURE Neutronics and Related Computer Codes", ORNL/TM-5887, Oak Ridge National Lab, August, 1977.

A listing with input for VENTURE sample problems.

10. "BRIEF, Basic Reconfigurable Interactive Editing Faclitty, Ver 2", Underware Ino., 84 Gainsborough St., Suite 103W, Boston, Mass., 02115 .

An excellent PC Editor for code development and editing.

11. "F77L FORTRAN 77 Language System, Ver 2.22", Lahey Compluter Systems, Inc., P.0. Box 6091, Incline Village, Nv. 89450-6091., (702) $831-2500$.

A very excellent FORTRAN compiler, providing rapid compliation and running.

12. "PLINK86PLUS Overlay Linker, Ver 2.24", Phoenix Technologles Ltd, 320 Norwood Park South, Norwood MA. 02062 (800)344-7200.

A multilevel overlay linker for PC's.

13. Nigg, D.W., INEL, EGGG Idaho Inc., fersonal Communication 
APPENDIX $\mathrm{I}$

FORTRAN LISTING OF DRIVER 


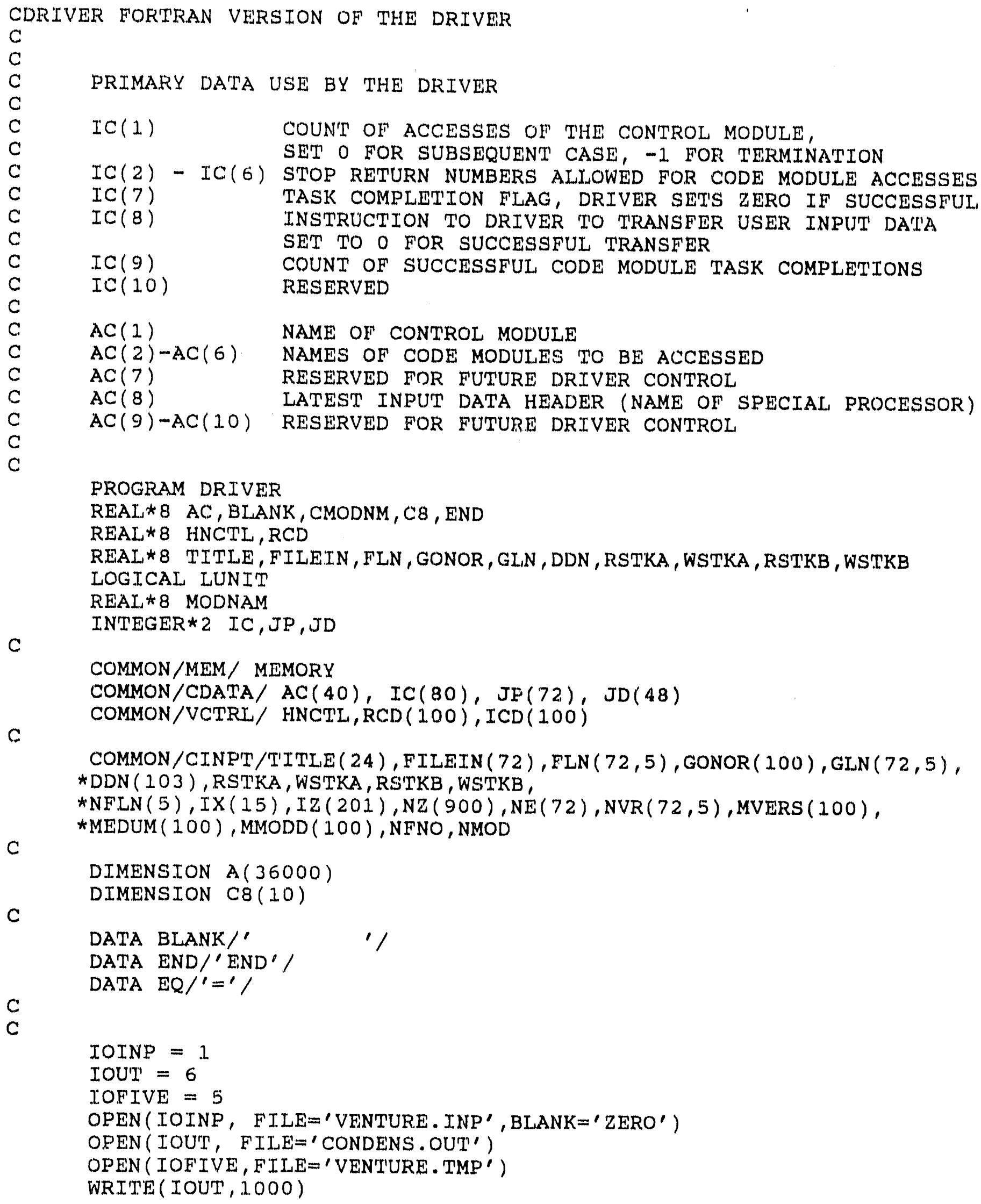




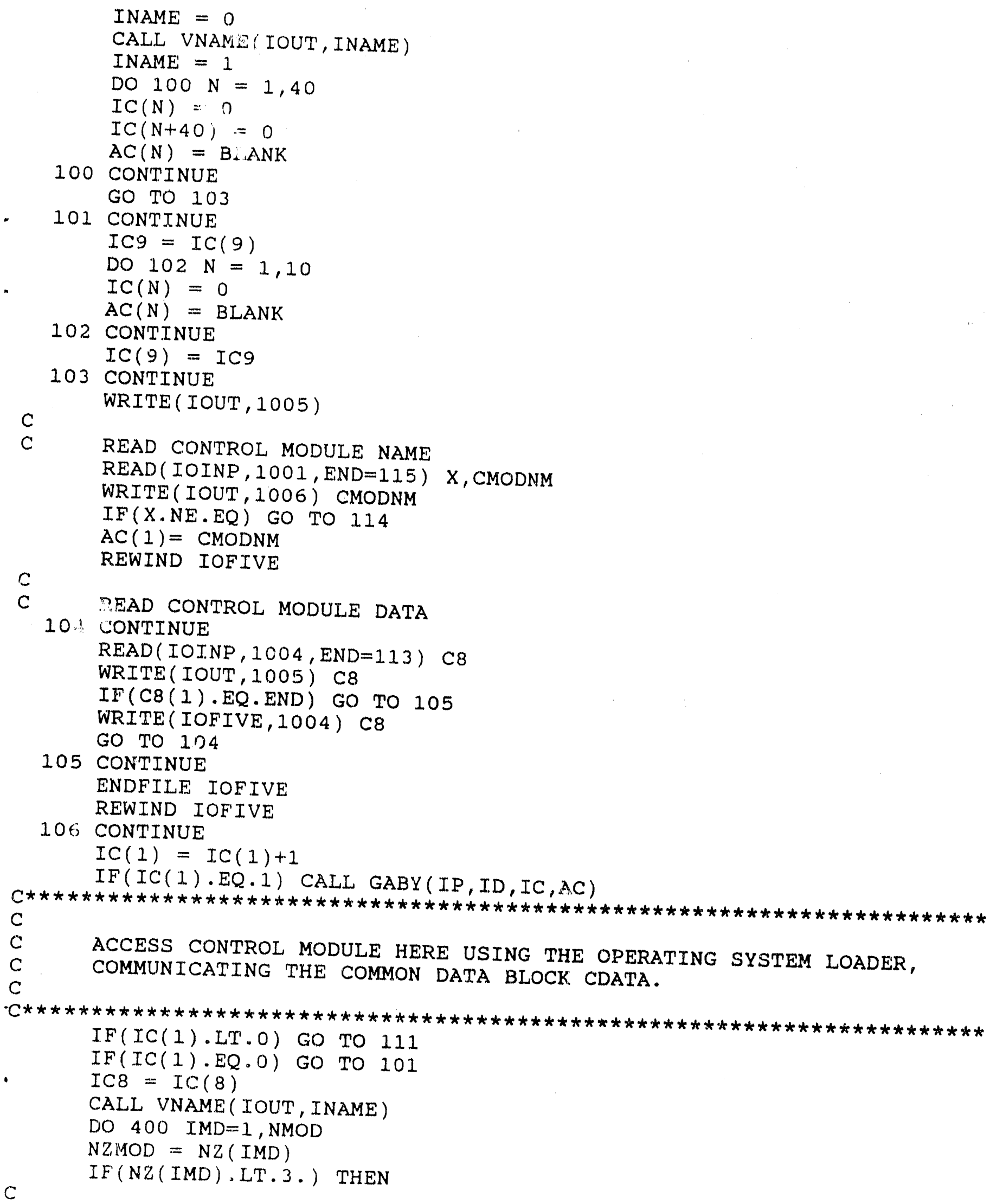


C READ INPUT OR SPECIAL PROCESSOR NAME.

INQUIRE (UNIT=IOFIVE, OPENED=LUNIT)

IF (.NOT.LUNIT) OPEN (IOFIVE, FILE='VENTURE.TMP')

READ (IOINP, 1004, END=110) C8

WRITE (IOUT, 1005) C8

$A C(8)=C 8(1)$

MODNAM $=C 8(1)$

IF (IC8.EQ.2) AC (2) $=C 8(1)$

REWIND IOFIVE

C

C

107 CONTINUE

READ (IOINP, 1004,END $=110$ ) C8

WRITE(IOUT, 1005) C8

IF (C8 (1). EQ.END) GO TO 108

WRITE(IOFIVE, 1004) C8

GO TO 1.07

108 CONTINUE

ENDFILE IOFIVE

REWIND IOFIVE

$I C(8)=0$

109 CONTINUE

$I C(7)=0$

ENDIF

GO TO $(210,220,230,400,400,260,270,280,290,400,310,320,330$,

* 400,350,400,400,400,390,400) NZMOD

210 CALL CLOSFI

CALL INPROSER (A, MEMORY)

GO TO 400

220 CONTINUE

GO TO 400

230 CALI FILEDTOR

GO TO 400

260 CALL CLOSFI

CALL CROSPROS (A, MEMORY)

GO TO 400

270 CLOSE ( 3)

CLOSE (5)

CLOSE ( 9 )

CLOSE ( 98 )

CALL CLOSFI

CAIL VENTNEUT ( $A$, MEMORY)

IF (IMD.NE.NMOD) THEN

CALL CLOSFI

CLOSE (23)

CLOSE (24)

C.LOSE ( 27 )

CLOSE ( 28 )

CLOSE ( 40$)$

OPEN ( 5 , FILE='VENTURE.TMP', BLANK='ZERO')

ENDIF

GO TO 400

280 CALL VALENEUT 
GO TO 400

290 CALL CLOSFI

CALI REACRATE (A, MEMORY)

GO TO 400

310 CALL VANCNEUT

GO TO 400

320 CALL CNTRODPO

GO TO 400

330 CALL CLOSFI

CALL EXPOSURE (A, MEMORY)

CLOSE (23)

CLOSE (24)

CLOSE ( 27)

CLOSE (28)

CLOSE $(40)$

GO TO 400

350 CALI PERTUBAT (A, MEMORY)

GO TO 400

390 CALL FUELMANG

400 CONTINUE

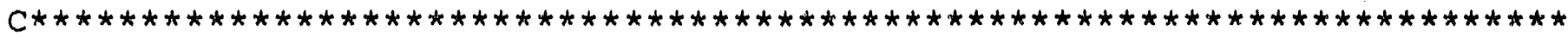

C

C ACCESS CODE MODULES HERE USING THE OPERATION SYSTEM LOADER -

C (MODULE NAMES ARE AC(2) THROUGH AC(6) UP TO A BLANK) ,

C. ADD 1 IC (9) FOR EACH SUCCESSFUL MODULE ACCESS,

C IF THE RETURN STOP NUMBER FROM AN ACCESSED MODULE AC(N) EXCEEDS

C THE ALLOWED VALUE IC(N), IC(7) IS SET TO THE RETURNED NUMBER AND

C THE CONTROL WODULE IS ACCESSED WITHOUT FURTHER CODE MODULE

C ACCESSES.

$C$

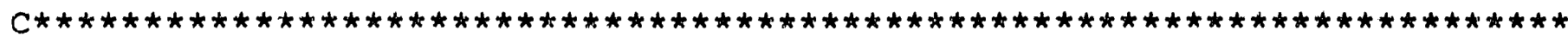

GO TO 215

110 CONTINUE

WRITE (IOUT, 1008)

GO TO 116

111 CONTINUE

WRITE (IOU', 1009)

GO TO 116

113 CONTINUE

WRITE ( IOUT, 1.007)

GO TO 116

114 CONTINUE

WRITE ( IOUT, 1003)

GO TO 116

115 CON'TINUE

WRITE (IOUT, 1002)

116 CONTINUE

CALL DELFIL

S'TOP

C

1000 FORMAT(' FORTRAN DRIVER FOR A MODULAR CODE SYSTEM FOR TESTING $\left.*(7-1-76)^{\prime}\right)$

1001 FORMAT $(A 1, A 8)$ 


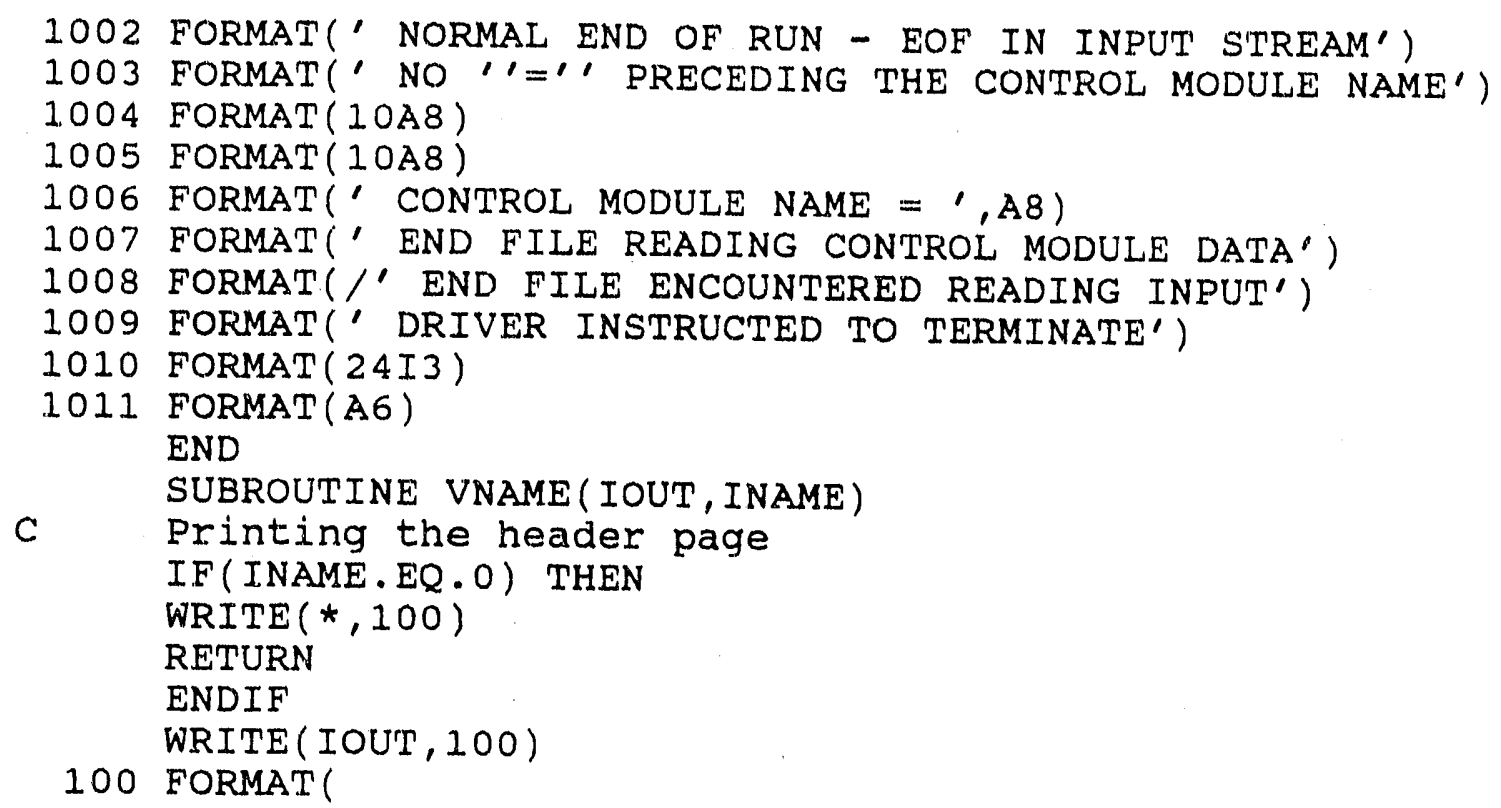


INTEGER* 2 IC, JP, JD, IB , IP, ID

GABY 50

REAL * 8 AC, AB

COMMON/MEM/ MEMORY

COMMON /CDATA/AC(40), IC(80), JP(72), JD(48)
DIMENSION IP(1), ID(1), IB(1), $A B(1)$

GABY 60

GABY 80

GABY 100

C

DO $100 \quad I=1,40$

$A C(I)=A B(I)$

$I C(I)=I B(I)$

$I C(I+40)=I B(I+40)$

100 CONTINUE

DO $110 \quad I=1,72$

$J P(I)=I P(I)$

110 CONTINUE

DO $120 \quad I=1,48$

$J D(I)=I D(I)$

C

120 CONTINUE

C GO TO THE MAIN PROGRAM OF THE CONTROL MODULE CALL CONTROL1

GABY 260

C.

C RETURN ROUTE FROM THE MAIN PROGRAM

DO $130 \quad I=1,40$

$A B(I)=A C(I)$

$I B(I)=I C(I)$

$I B(I+40)=I C(I+40)$

C

130 CONTINUE

C RETURN TO THE DRIVER

RETURN

GABY 120

GABY 130

GABY 140

GABY 150

GABY 160

GABY 170

GABY 1.80

GABY 190

GABY 200

GABY 210

GABY 220

GABY 230

GABY 240

GABY 250

GABY 270

GABY 280

GABY 290

GABY 300

GABY 310

GABY 320

GABY 330

GABY 340

GABY 350

GABY 360

END

GABY 370 
APPENDIX IV

VENTURE SUBROUTINES

(from reference 5) 
THE ACCESS, CONTROL, AND GENERAL PURPOSE ROUTINES

\begin{tabular}{|c|c|}
\hline MAIN & ENTRY POINT TO NEUTRONICS CODE BLOCK. \\
\hline & CALLS ERRSET, TIMER, DOPC, IONO, VENT, DRIV \\
\hline IONO & ASSIGNS INPUT/OUTPUT UNIT NUMBERS \\
\hline VENT & $\begin{array}{l}\text { ACCESSES CODE BLOCK CONTROL INFORMATION } \\
\text { CALLS SKER, FERR }\end{array}$ \\
\hline DRIV & $\begin{array}{l}\text { PASSES INFORMATION TO THE CONTROLLER ROUTINE } \\
\text { ALLOCATES CORE STORAGE }\end{array}$ \\
\hline DIFF & $\begin{array}{l}\text { CALLS GETCOR, ROXX, ROXY, DIFF, DOPC, FRECOR } \\
\text { CONTROLS THE CALCULATION }\end{array}$ \\
\hline & $\begin{array}{l}\text { CAILS CORE, MAC1, CON1, PHIA, ORLX, COMC, LCAL, FLXR, } \\
\text { FXSR, BSQV, AJNT, PROS, DOPC, OUTR, DSDF, DCID, } \\
\text { DIMS, AJDS, FLRD, ADN1, EDIT, SAV1, PERT, JERT, } \\
\text { FERR, TIMER }\end{array}$ \\
\hline CORE & $\begin{array}{l}\text { DETERMINES STORAGE REQUIREMENTS AND DATA HANDLING MODES. } \\
\text { CALLS CORI, CORP, GNAM, CORD, CORB, DDSP, DASU, SKER, JPRT, } \\
\text { FERR. }\end{array}$ \\
\hline DASU & SETUP DIRECT ACCESS FILES \\
\hline EASU & $\begin{array}{l}\text { SETUP DIRECT ACCESS FILES } \\
\text { CALIS DOPC, FERR }\end{array}$ \\
\hline TIMER & SERVICE ROUTINE FOR COMPUTER TIME, ETC. \\
\hline STOR & SERVICE ROUTINE FOR MOVING DATA IN MAIN MEMORY \\
\hline SKER & FILE MANAGEMENT RELATED ERROR MESSAGES \\
\hline FERR & ALL OTHER FATAL ERROR MESSAGES \\
\hline KEEP* & DUMMY ROUTINE USED TO OUTFOX TH \\
\hline
\end{tabular}

THE INPUT/OUTPUT ROUTINES

DOPC INITIALIZES, OPENS, AND CLOSES DATA FILES

ENTRY ROXY COMMUNICATES DATA ARRAYS

CALIS SEEK, RITE, DEFILE, CLOSDA, (FBSAM AND ENTRIES)

RITE

DATA TRANSFER MANAGER AND WRITES DATA (FORTRAN WRITE) -CALLED BY MOST ROUTINES.

ENTRY REED READS DATA (FORTRAN READ) - CALLED BY MOST

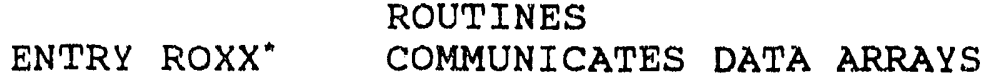

CALLS CRIT, CRED, (FBSAM, AND ENTRIES)

INTERFACE DATA F'ILES MANAGER

CALLS RITE, REED

CRIT* ASSEMBLY LANGUAGE ROUTINE FOR CORE TO EXTENDED CORE DATA TRANSFER (SEE SECTION 203 FOR THE FORTRAN EQUIVALENT)

ENTRY CRED EXTENDED CORE TO CORE DATA TRANSFER

DEFILE* ASSEMBLY LANGUAGE ROUTINE TO EXECUTE THE FORTRAN DEFINE FILE TATEMENT USING PROBLEM DEPENDENT VARIABLES (OPENS DIRECT ACCESS FILES) - ACCESSES SYSTEM ROUIINE IHCEDIOS

CLOSDA * ASSEMBLY LAANGUAGE ROUTINE TO CLOSE DIRECT ACCESS FILES

FBSAM* LOCAL I/O ROUTINE USED ALONG WITH THE I/O PACKAGE TO PRODUCE SPECIAL, CAPABILITY 


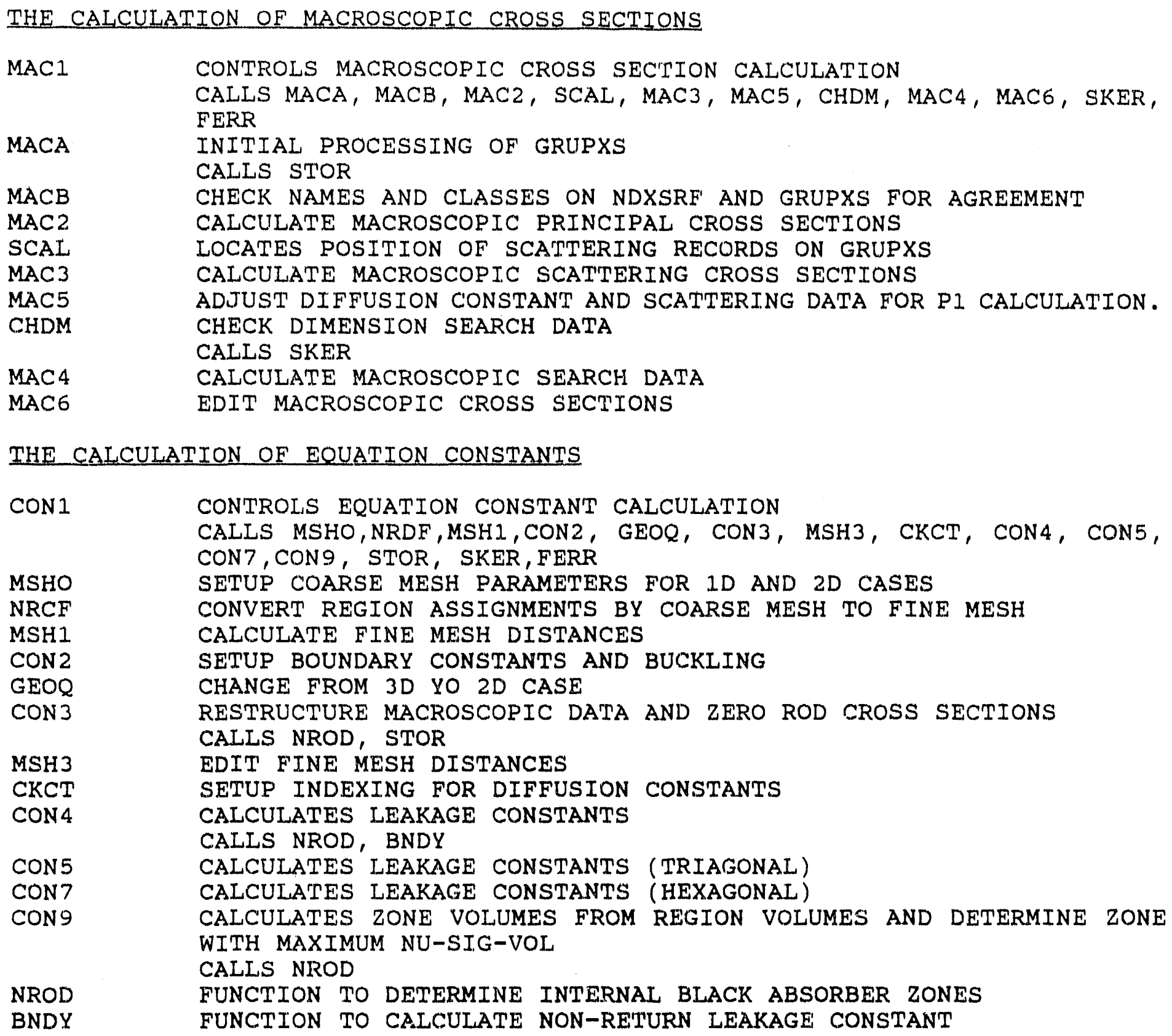

NROD

BNDY CONVERT REGION ASSIGNMENTS BY COARSE MESH TO FINE MESH 


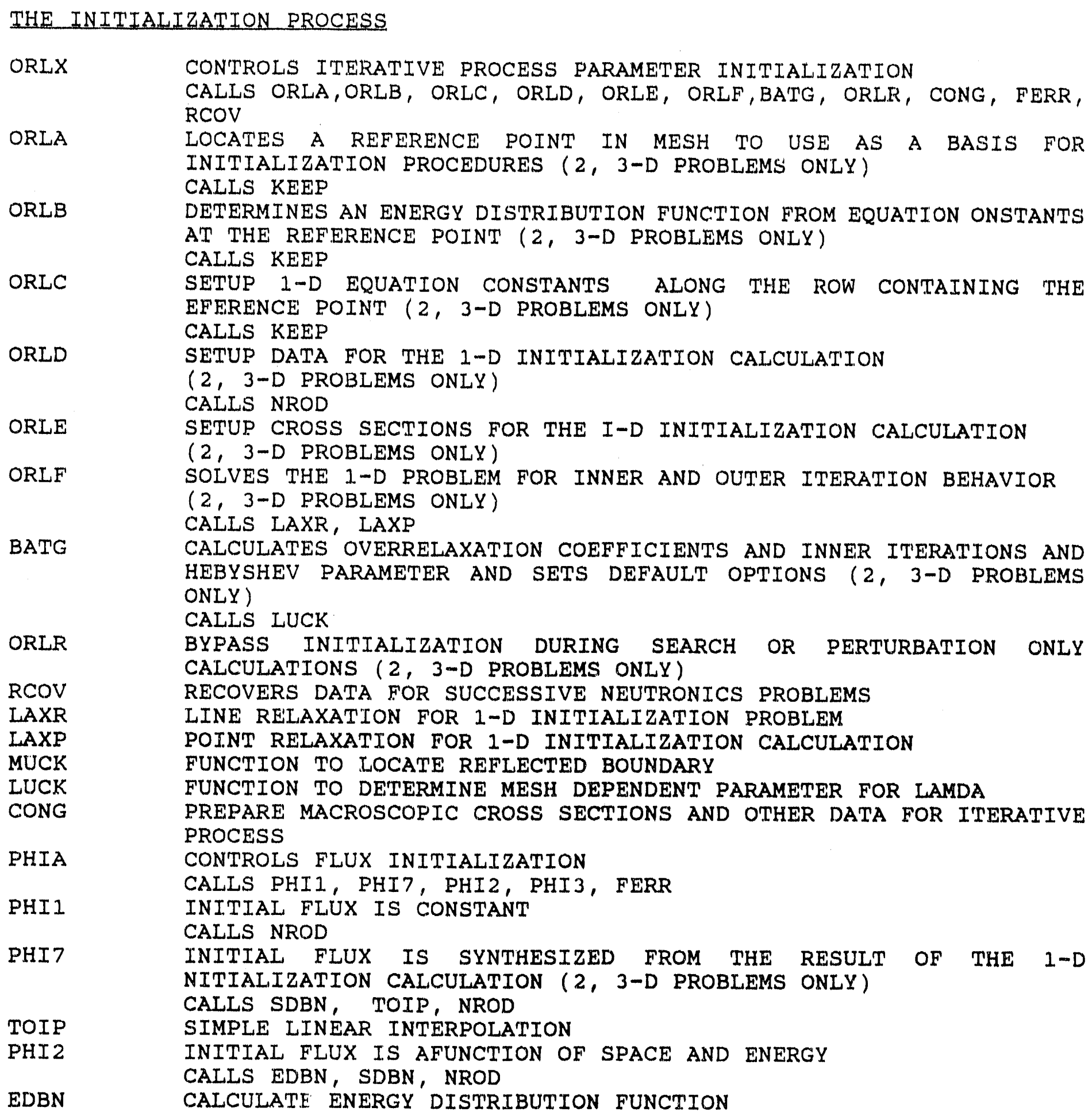

ORLC SETUP 1-D EQUATION CONSTANTS ALONG THE ROW CONTAINING THE EFERENCE POINT ( $2,3-D$ PROBLEMS ONLY)

ORLR

BYPASS INITIALIZATION DURING SEARCH OR PERTURBATION ONLY CALCULATIONS ( $2,3-D$ PROBLEMS ONLY)

RCOV

LAXR

LAXP

MUCK

LUCK

CONG

PHIA

RECOVERS DATA FOR SUCCESSIVE NEUTRONICS PROBLEMS

LINE RELAXATION FOR 1-D INITIALIZATION PROBLEM

POINT RELAXATION FOR 1-D INITIALIZATION CALCULATION

FUNCTION TO LOCATE REFLECTED BOUNDARY

FUNCTION TO DETERMINE MESH DEPENDENT PARAMETER FOR LAMDA

PREPARE MACROSCOPIC CROSS SECTIONS AND OTHER DATA FOR ITERATIVE PROCESS

PHI 1

CONTROLS FLUX INITIALIZATION

CALLS PHI1, PHI7, PHI2, PHI3, FERR

INITIAL FLUX IS CONSTANT

CALLS NROD

PHI7 INITIAL FLUX IS SYNTHESIZED FROM THE RESULT OF THE 1-D NITIALIZATION CALCULATION ( $2,3-D$ PROBLEMS ONLY)

CALLS SDBN, TOIP, NROD

TOIP SIMPLE LINEAR INTERPOLATION

PHI2 INITIAL FLUX IS AFUNCTION OF SPACE AND ENERGY

EDBN CALLS EDBN, SDBN, NROD 


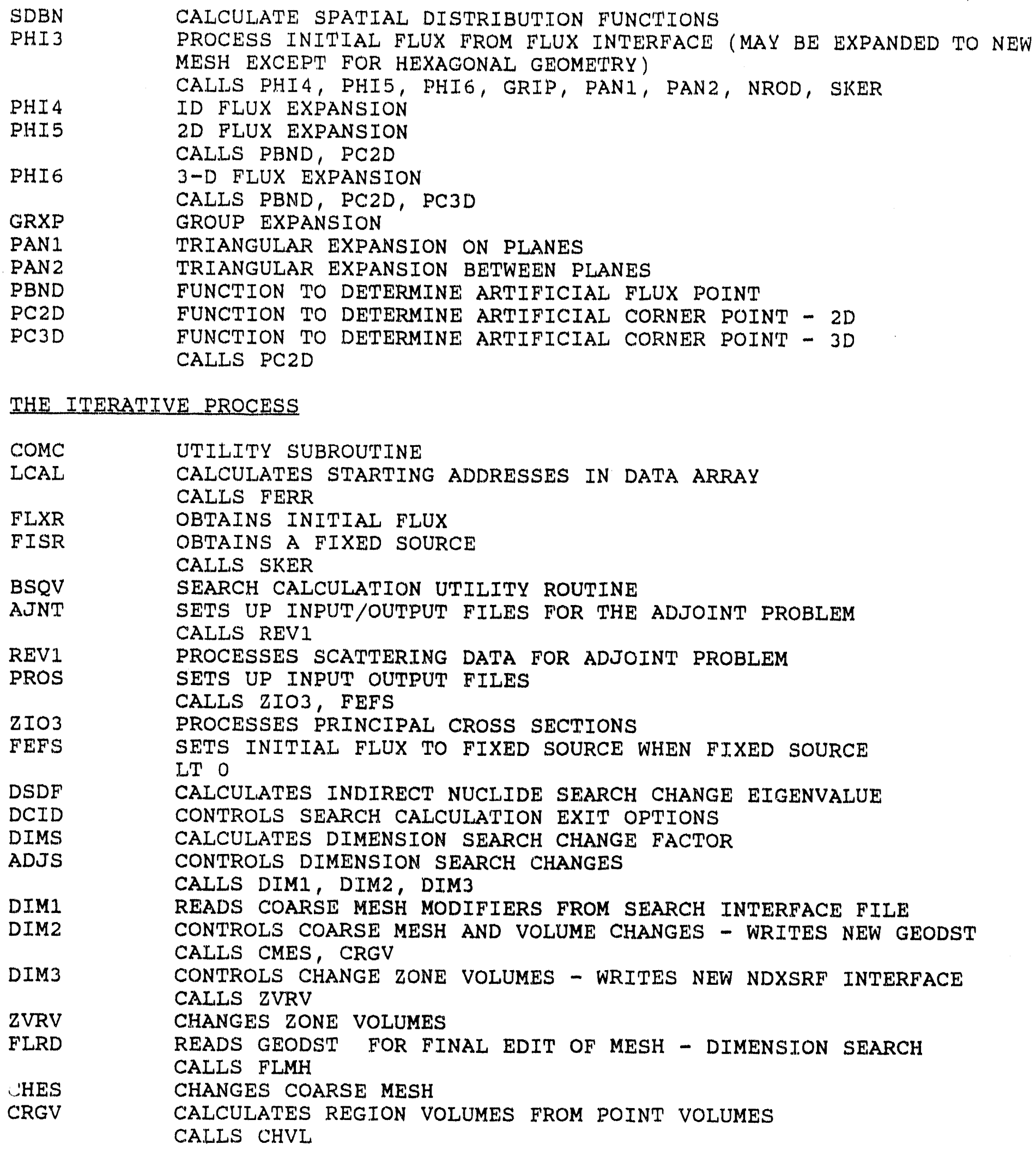


CHVL

FLMH

OUTR

BALC

ZINS

CHBF

CHEV

RDAB

LTRG

ITRP

BHAV

JUSB

ATED

FFGG

RDUE

RELX

OELX

NEWB

FSOR

SSOR

PSOR

F'LUX

MUEX

ETR 1

ETR2

SGDA

DOIN

RRES

WRES

PREC

$A D N 1$

ADN 2

ADN 3

INR 1

LOU1

FOU1

SOU1

POU1.

LEKI
CHANGES REGION VOLUMES

EDITS FINAL MESH - DIMENSION SEARCH

OUTER ITERATION CONTROLLER

CALLS DOIN, ZINS, FSOR, SSOR, FLUX, PSOR, JUSB, BALC, ITRP, WRES, PREC, MUEX, CHEV, ETR1, ETR2, ATED, SGDA, FERR

NEUTRON BALANCE EQUATION

CALCULATES THE DIRECT SEARCH PROBLEM EIGENVALUE

CHEBYSHEV ACCELERATION ROUTINE

CHEBYSHEV ACCELERATION ROUTINE

CALCULATES ROD ABSORPTIONS

CALCULATES IN-LEAKAGE FOR TRINAGULAR GEOMETRY

ASSESSES FLUX CONVERGENCE

CALLS FFGG, BHAV

CALCULATES ITERATIVE CONVERGENCE PARAMETERS

OVERRELAXATION COEFFICIENT CONTROL,

EDITS ITERATION DATA

CALCULATES FLUX EXTRAPOLATION FACTORS

RESIDUE ESTIMATE OF THE MULTIPLICATION FACTOR

SOLVES FOR THE FLUX VALUES ALONG A ROW AND OVERRELAXES THEM

SOLVES FOR THE FLUX VALUES ALONG A ROW NO OVERRELLAXATION

CALCULATES NEW OVERRELAXATION FACTORS

FISSION SOURCE CALCULATION CONTROLLEIR

CALLS FOU1, FOU2, FOU3, FOU4, FOU5, FOU6

SCATTERING SOURCE CALCULATION CONTROL

CALLS SOU1, SOU2, SOU3, SOU4, SOU5, SOUE

P-1 SCATTERING SOURCE CALCULATION CONTROL

CALISS POU1, POU2, POU3, POU4, POU5

INNER ITERATION CONTROL

CALLS INR1， INR2，INR3，INR4， INR5， INR6, INRX, BHAV

EXTRAPOPLATION PARAMETER PROCESSING

SINCL I ERROR MODE FLUX EXTRAPOLATION

DOUBLE ERROR MODE FLUX EXTRAPOLATION

SAVES AND RETRIEVES DATA DURING DIRECT NUCLIDE SEARCH

FLUX CALCULATION UTILITY ROUTINE

READS RESTART FILE

WRI'TES RESTART FILE

CALCULATES ONE-DIMENSIONAL SWEEP PARAMETERS

CONTROLLER FOR UPDATING ATOMIC DENSITIES

UPDATES ATOMIC DENSITIES

EDITS ATOMIC DENSITIES

INNER ITERATION CONTROL ( 1 ROW STORED MODE)

CALLS LOU1, RDUE, RELX, LEK1, CHEV, OELX, NEWB

IN-LEAKAGE CALCULATION

FISSION SOURCE CALCULATION

SCATTERING SOURCE CALCULATION

P-1 SCATTERING SOURCE CALCULATION

OUT-LEAKAGE CALCULATION 
INNER ITERATION CONTROL (ALL DATA STORED MODE)

FOU2

LOU2

SOU2

POU2

LEK2

INR 3

LOU 3

FOU3

SOU 3

POU 3

LEK 3

INR4

LOU 4

LTRG

FOU 4

SOU 4

POU 4

LEK 4

J $1 \mathrm{C} 4$

QDUE

QEIX

INR5

LOU5

FOU 5

SOU 5

POU5

J1C5

LEK5

INR6

FOU6

SOU6

DELX

INRX

CALLS LOU2, RDUE, RELX, LEK2, CHEV, RDAB, OELX, NEWB FISSION SOURCE CALCULATION

IN-LEAKAGE CALCULATION

SCATTERING SOURCE CALCULATIUN

P-1 SCATTERING SOURCE CALCULIAIION

OUT-IEAKAGE CALCULATION

INNER ITERATION CONTROL (SPACE PROBLEM DATA STORED MODE)

CALLIS LOU3, RDUE, RELX, LEK3, CHEV, LTRG, RDAB, OELX, NEWB IN-LEAKAGE CALCULATIION

FISSION SOURCE CALCULATION

SCATTERING SOURCE CALCULATION

P-1 SCATTERING SOURCE CALCULATION

OUT-LEAKAGE CALCULATION

INNER ITERATION CONTROL (MULTIPLE PLANE DATA STORED MODE)

CALISS LOU4, QDUE, QELX, LEK4, SOUX, J1C4, CHEV, LTRG, RDAB, NEWB IN-LEAKAGE CALCULATION

SPECIAL IN-LEAKAGE CALCUIAITION FOR TRIANGULAR GEOMETRY

FISSION SOURCE CALCULATION

SCATTERING SOURCE CALCULATION

P-I SCATTERING SOURCE CALCULATION

OUT-IEAKAGE CALCULATION

DEL DOT J CALCULATION

ACCESSES RESIDUE CALCULATION

CALLS RDUE

ACCESSES FLUC CALCULATION

CALLS RELX, OELX

INNER ITERATION CONTROL (MULTI-ROW STORED MODE)

CALLS LOU5, RDUE, RELX, LEK5, JIC5, SHIV, OELX, NEWB

IN-LEAKAGE CALCULATION

FISSION SOURCE CALCULATION

SCATTERING SOURCE CALCULATION

P-1 SCATITERING SOURCE CALCULATION

DEL DOT I CALCULATION

OUT-IUAKAGE CALCULATION

CONTROLIE'R ROUTINE FOR THE SPECIAL L-D PROCEDURE

CALLS CHEV

FISSION SOURCE CALCULATION

SCATTERING SOURCE CALCULATION

LINE RELAXATION WITHOUT OVERRELAXATION

INNER ITERATION CONTROL (MULTI-LEVEL DATA TRANSFER MODE)

CALLS LOUX, RDUE, RELX, LEKX, SOUZ, JICX, CHEV, RDAB, OELX, NEWB 


$\begin{array}{ll}\text { LOUX } & \text { IN-LEAKAGE CALCULATION } \\ \text { FOUX } & \text { FISSION SOURCE CALCULATION } \\ \text { SOUY } & \text { SCATTERING SOURCE CALCULATION } \\ \text { SOUZ } & \text { SCATSERING SOURCE CALCULATION } \\ \text { POUX } & \text { P-1 SCATTERING CALCULATION } \\ \text { LEKX } & \text { OUT-LEAKAGE CALCULATION } \\ \text { J1CX } & \text { DEL DOT J CALCULATION }\end{array}$

\section{IHE EDIT ROUTINES}

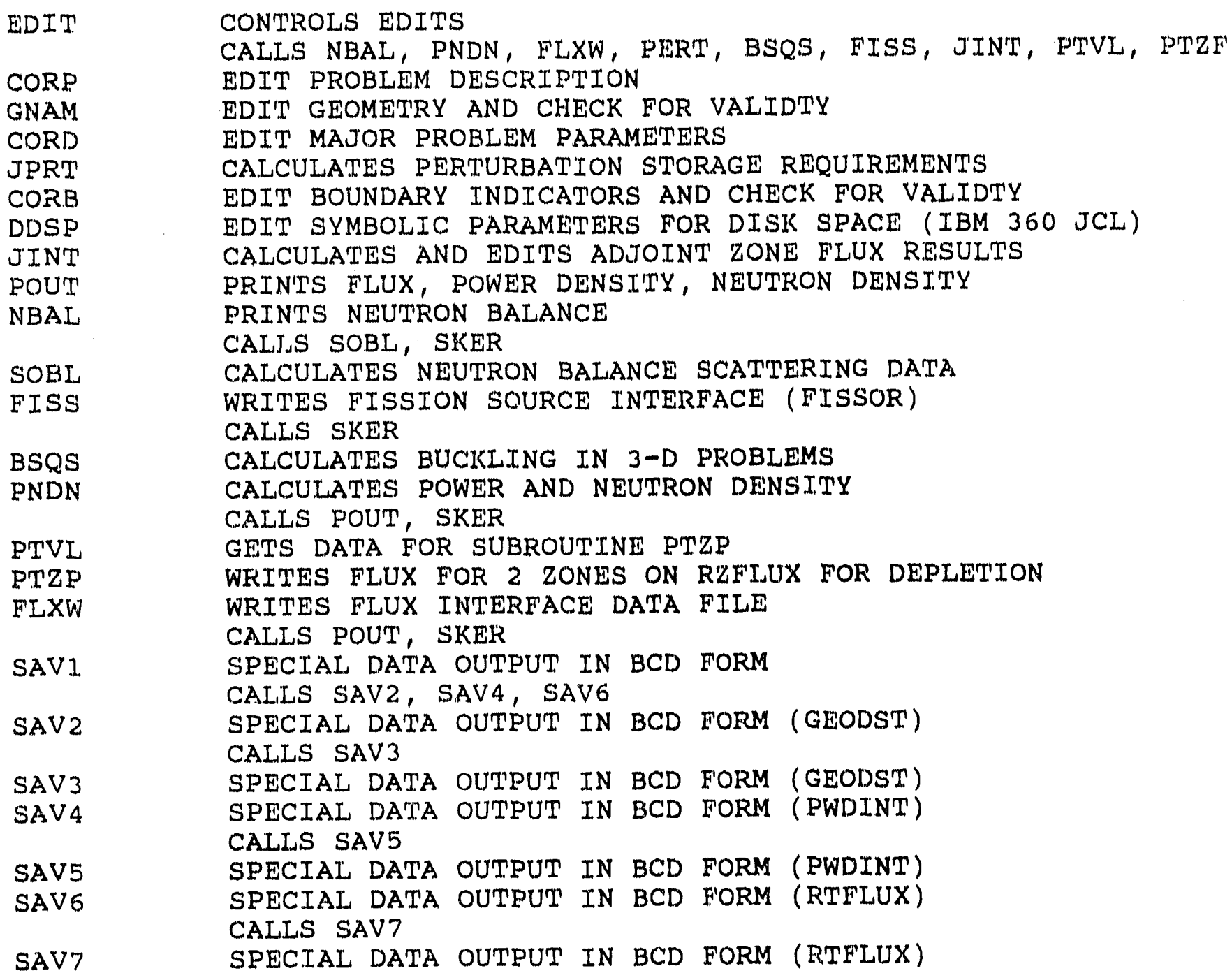




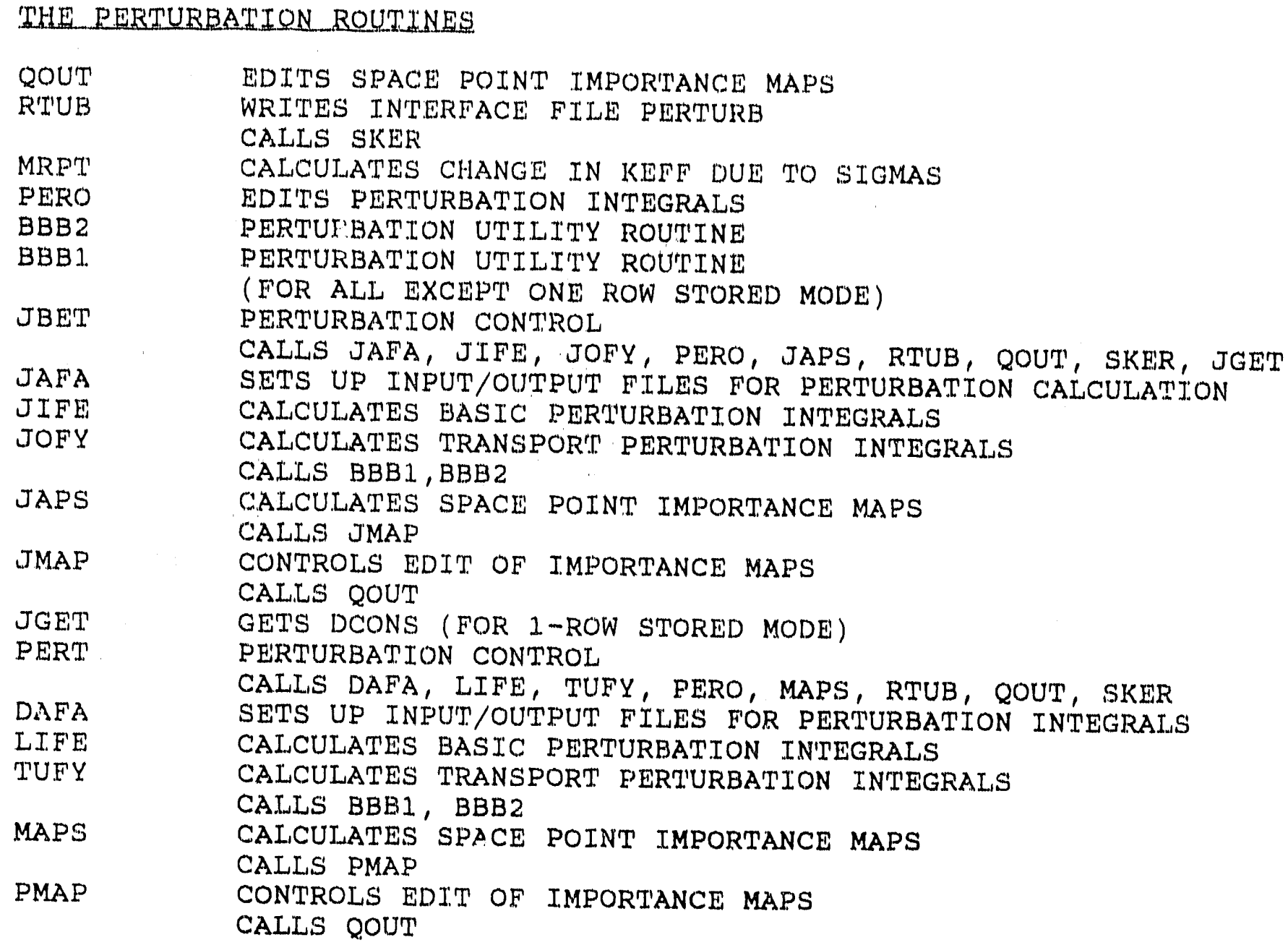




\section{LABELED COMMON BLOCKS}

CNTRL VCTRL

MGMTIO

IOUNT

AFLUY

AOSUB

LIMITS

ADRES

FSWAP

DEASU

COMSAM

USRID

* NOT USED BY VENTURE \PC 
APPENDIX III.

BURNER SUBROUTIYES

(FROM REF.8) 
BURNER SUBROUTINE DESCRIPTION

\begin{tabular}{|c|c|}
\hline \multirow{3}{*}{$\begin{array}{l}\text { ANOR } \\
\text { ARRI }\end{array}$} & DETERMINE NORM OF N \\
\hline & SUM INVENTORY AND REACTION \\
\hline & $\begin{array}{l}\text { FISSION, PRODUCTION, } \\
\text { ABSOLUTE NUCLIDE }\end{array}$ \\
\hline$U \times E$ & ITE CONDENSED EDIT \\
\hline IX & ORMAL EXPOSURE CALCULATION \\
\hline GXS & ROCESS NEXT-TO-LATEST GRUPXS \\
\hline INP & ITIIAL INTERFACE PROCESSING \\
\hline & UPXS, AND EXPOSE) AND DATA PREPARATION \\
\hline Mov & ONTINUOUS FUELING EXPOSURE CALCULATION \\
\hline I & $\begin{array}{l}\text { CONTROL GEOMETRY (GEODST) AND POINT FLUX RTFLUX) } \\
\text { PROCESSING FOR POINT CALCULATION (METHOD } 1 \text { ) }\end{array}$ \\
\hline BPIB & $\begin{array}{l}\text { CONTROL POINT FLUX (RZFLUX-MODIFIED) PROCESSING } \\
\text { FOR POINT CALCULATION (METHOD 2) }\end{array}$ \\
\hline BPIC & INITIAL DENSITY PREPARATION, COMPUTE REACTIO \\
\hline & $\begin{array}{l}\text { RATES AND SETUP STORAGE FOR POINT EXPOSURE AN } \\
\text { SHUTDOWN CALCULATION }\end{array}$ \\
\hline PIN & CONTROL SETUP FOR POINT EXPOSURE AND SHUTDOWN \\
\hline BRCI & $\begin{array}{l}\text { OBTAIN EXPOSURE CONTROL INFORMATION } \\
\text { INTERFACE CONTROL }\end{array}$ \\
\hline Sחi & ETUP DYNAMIC DATA STORAGE SPACE \\
\hline RNA & $\begin{array}{l}\text { COMPUTE SPECIFIC REACTION RATES FOR ABSORPTION, } \\
\text { FISSION, NU-FISSION, }(N, G),(N, A),(N, P),(N, 2 N) \text {, } \\
(N, D), \text { AND }(N, T)\end{array}$ \\
\hline$D$ & EDIT SPECIFIC REACTION RATES \\
\hline$F$ & $\begin{array}{l}\text { SETUP INTERNAL CROSS-REFERENCING INFORMATION FOR } \\
\text { ABSOLUTE NUCLIDE, NUCLIDE CLASS, AND ZONF }\end{array}$ \\
\hline RNO & PREPARE AND EDIT FINAL SUMMARY TABLE \\
\hline RNS & $\begin{array}{l}\text { DETERMINE STORAGE REQUIRED AND MODE OF SOLUTION } \\
\text { AND INITIALIZE DIRECT ACCESS UNITS IF NEEDED }\end{array}$ \\
\hline 3RNT & PRE-WRITE DIRECT ACCESS UNITS IF NEEDED \\
\hline 3RNW & $\begin{array}{l}\text { EDIT CONTENTS OF EXPOSE FILE - CHECKS DECAX, } \\
\text { YIELD, AND MATRIX DATA FOR ERRORS }\end{array}$ \\
\hline RNAX & $\begin{array}{l}\text { SETUP DECAY CONSTANTS AND CORRESPONDENCE BETWEEN } \\
\text { DENSITY AND EXPOSURE DATA }\end{array}$ \\
\hline BRNY & EDIT ATOM DENSITIES \\
\hline BRNZ & $\begin{array}{l}\text { PROCESS ZNATDN AND WRITE INITIAL DENSITIES } \\
\text { SCRATCH ONE ZONE/SUBZONE AT A TIME }\end{array}$ \\
\hline 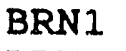 & OVERALL CALCULATION CONTROL \\
\hline SRN3 & PROCESS RZFLUX AND WRITE ZC \\
\hline & $\begin{array}{l}\text { SCRATCH ONE GROUP AT A TIME - E } \\
\text { POWER ADJUSTMENT }\end{array}$ \\
\hline & HECK NUCLIDE NAMES AND \\
\hline & $\begin{array}{l}\text { OPY PRINCIPAL CROSS SECTIONS FROM GRUPXS } \\
\text { CRATCH }\end{array}$ \\
\hline
\end{tabular}




\begin{tabular}{|c|c|}
\hline BRPF & $\begin{array}{l}\text { COMPUTE SPECIFIC REACTION RATE FOR FISSION IN } \\
\text { ENERGY RANGES OF FIELD DATA FOR POINT CALCULATION }\end{array}$ \\
\hline BRRF & $\begin{array}{l}\text { COMPUTE SPECIFIC REACTION RATE FOR FISSION IN } \\
\text { ENERGY RANGES OF YIELD DATA }\end{array}$ \\
\hline URN & CONTROLS EXPOSURE AND SHUTDOWN CALCULATION \\
\hline $\mathrm{N}$ & ADDITIONAL \\
\hline & $\begin{array}{l}\text { ZNATDN) AND COMPUTE REACTION RATES AND SETUP } \\
\text { STORAGE FOR EXPOSURE AND SHUTDOWN CALCULATION }\end{array}$ \\
\hline $\begin{array}{l}\text { BZT1 } \\
\text { BZT2 }\end{array}$ & $\begin{array}{l}\text { DETERMINE IF ZNTEMP EXISTS AND CHECK INPUT DATA } \\
\text { PROCESS TEMPERATURES FROM ZNTEMP }\end{array}$ \\
\hline CHEK & DEBUG FLUX CHECK FOR POINT CALCULATION (METHOD 1) \\
\hline CMOV & $\begin{array}{l}\text { CHECK NUCLIDE SET REFERENCES FOR } \\
\text { FUELING MODEL }\end{array}$ \\
\hline MPH & COMPARE 2 HOLLERITH ARRAYS \\
\hline CMPI & COMPARE 2 INTEGER ARRAYS \\
\hline EPH1 & $\begin{array}{l}\text { COPY ONE SET OF EXPOHT DATA FROM ONE UNIT TO } \\
\text { ANOTHER }\end{array}$ \\
\hline CP & EDIT ONE SET OF EXPOHT DATA \\
\hline DE & $\begin{array}{l}\text { SETUP AND CHECK INPUT PARAMETERS FOR CONTINUOUS } \\
\text { FUELING MODEL }\end{array}$ \\
\hline OE & EXPOSURE BY VARIOUS METHODS \\
\hline DOF & $\begin{array}{l}\text { SCRATCH FILE DATA TRANSFER MANAGEMENT FOR SPECIAL } \\
\text { ACCESS METHODS (NOT SEQUENTIAL) }\end{array}$ \\
\hline $\mathrm{OSH}$ & SHUTDOWN BY VARIOUS METHODS \\
\hline DOWN & SHUTDOWN CALCULATION \\
\hline ECHK & CHECK NEUTRON ENERGY GROUP STRUCTURE \\
\hline EDED & EDIT SECONDARY ENERGY DEPOSITION DATA FROM EXE \\
\hline EDEP & SETUP FOR SECONDARY ENERGY DEPOSITION EDITS \\
\hline EPFD & $\begin{array}{lll}\text { SET DEFAULT } & \text { VALUE FOR } & \text { ENERGY/FISSION } \\
\text { ENERGY/CAPTURE IF NECESSARY } & \end{array}$ \\
\hline $\begin{array}{l}\text { EPH } 2 \\
\text { ESET }\end{array}$ & $\begin{array}{l}\text { EDIT MAXIMUMS AND SYSTEM TOTALS OF EXPOHT DATA } \\
\text { DETERMINE WHICH ENERGY GROUP NUMBER IS CUTOFF AND } \\
\text { FRACTIONAL PART FOR FLUENCE CALCULATION }\end{array}$ \\
\hline ETAB & CALCUL;ATE AND EDIT SECONDARY ENERGY DEPOSITION \\
\hline EXPH & SETUP AND CONTROL FOR WRITING INTERFACE EXPOHT \\
\hline$R_{1}$ & WRITE FATAL ERROR MESSAGE AND STOP \\
\hline FLUC & $\begin{array}{l}\text { FUNCTION TO DETERMINE } \\
\text { CONSTANT }\end{array}$ \\
\hline $\begin{array}{l}\text { FLUE } \\
\text { FOUL }\end{array}$ & $\begin{array}{l}\text { SUM ZONE FLUX OVER RANGE OF GROUPS SPECIFIED } \\
\text { EDIT MONITORING INFORMATION }\end{array}$ \\
\hline GCHK & $\begin{array}{l}\text { CHECK FOR IMPLEMENTED } \\
\text { CALCULATION (METHOD 1) }\end{array}$ \\
\hline & OBTAIN ZONE CLASSES FROM GEODST \\
\hline & CHECK FOR UNIQUENESS IN \\
\hline & $\begin{array}{l}\text { FUNCTION TO ASSIGN A REAL VARIABLE TO AN INTH } \\
\text { VARIABLE LOCATION WITHOUT TYPE CONVERSION }\end{array}$ \\
\hline
\end{tabular}




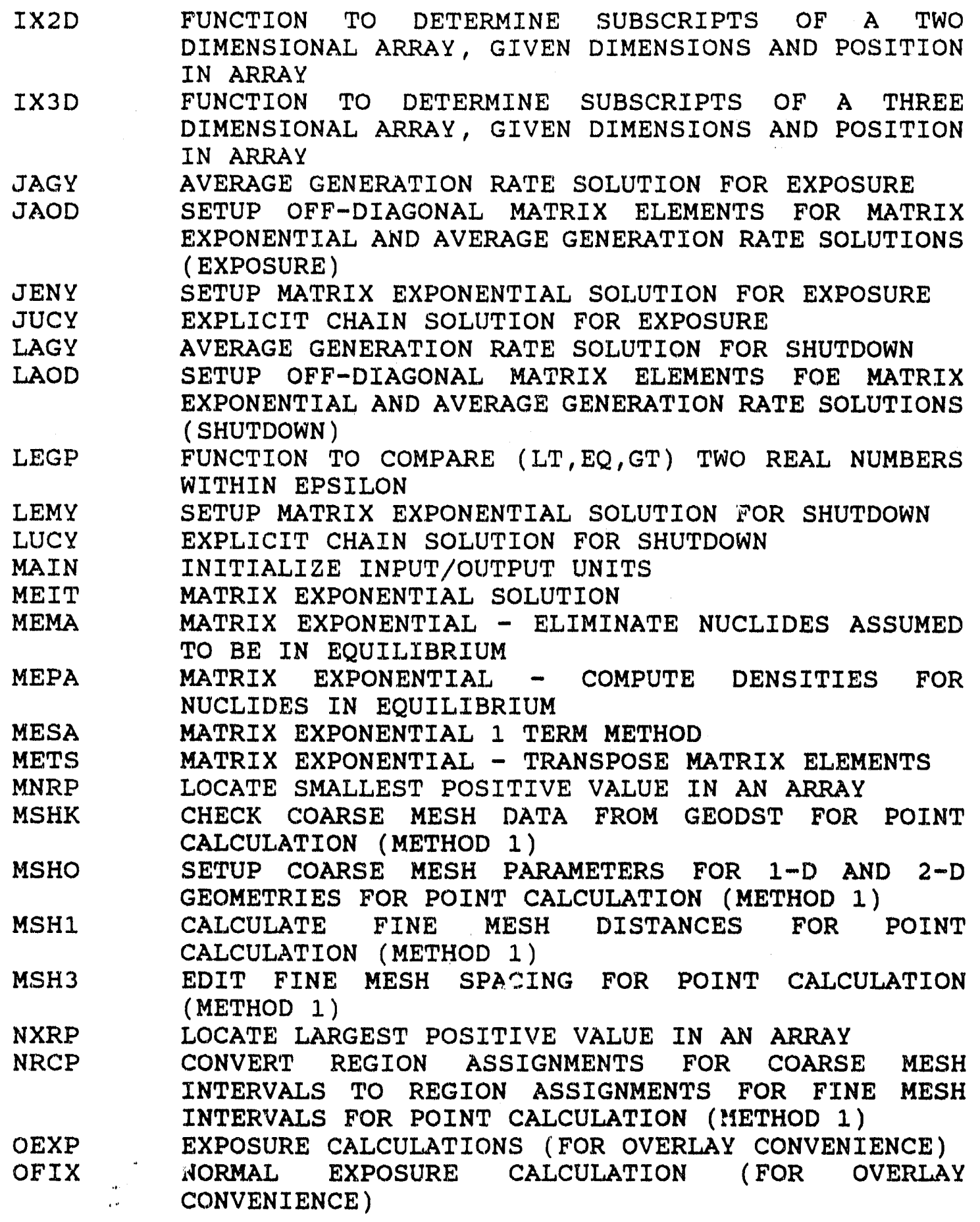




\begin{tabular}{|c|c|}
\hline OMOV & $\begin{array}{l}\text { CONTINUOUS } \\
\text { CONVENIENCE) }\end{array}$ \\
\hline OOWN & SHUTDOWN CALCULATION (FOR OVERLAY CONVENIENCE) \\
\hline PARI & EDIT START AND END OF STEP INVENTORY AND REACTION \\
\hline PDPT & CALCULATE POWER DENSITY \\
\hline $\begin{array}{l}\text { PDST } \\
\text { PFIX }\end{array}$ & $\begin{array}{l}\text { POWER DENSITY STATISTICS FOR POINT CALCULATION } \\
\text { POINT EXPOSURE CALCULATION }\end{array}$ \\
\hline PGEO & $\begin{array}{l}\text { PROCESS GEODST GEOMETRY FILE } \\
\text { CALCULATION (METHOD } 1 \text { ) }\end{array}$ \\
\hline PLOC & $\begin{array}{l}\text { LOCATE POINTS WITHIN SELECTED ZONES AND COMPUTE } \\
\text { POINT VOLUMES FOR POINT CALCULATION (METHOD } 1 \text { ) }\end{array}$ \\
\hline PNAW & $\begin{array}{l}\text { WRITE POINT NUCLIDE DENSITIES ON INTERFACE FILE } \\
\text { PTATDN FOR POINT CALCULATION }\end{array}$ \\
\hline PONI & EDIT FEED AND DISCHARGE RA'TES IN KG/DAY \\
\hline POWL & ACCUMULATE POWER AND LOCATE MAXIMUM POWER DENSITY \\
\hline POWN & POINT SHUTDOWN CALCULATION \\
\hline POWP & $\begin{array}{l}\text { ACCUMULATE POWER ALONG PATH FOR CONTINUOS FUELING } \\
\text { MODEL }\end{array}$ \\
\hline PPOE & $\begin{array}{l}\text { EDIT POWER, ACTINIDE FEED RATE, AND EXPOSURE BY } \\
\text { ZCNE PATH AND SUBZONE PATH FOR CONTINUOUS FUELING } \\
\text { MODEL }\end{array}$ \\
\hline PRNA & $\begin{array}{l}\text { COMPUTE SPECIFIC REACTION RATES FOR ABSORPTION, } \\
\text { FISSION, NU*FISSION, (N,G), (N,A), }(N, 2 N),(N, D), \\
\text { AND }(N, T) \text { FOR POINT CALCULATION }\end{array}$ \\
\hline PRND & $\begin{array}{l}\text { EDIT SPECIFIC REACTION RATES FOR } \\
\text { CALCULATION }\end{array}$ \\
\hline PRNS & $\begin{array}{l}\text { DETERMINE STORAGE REQUIRED AND MODE OF SOLUTION } \\
\text { AND INITIALIZE DIRECT ACCESS UNITS IF NEEDED FOR } \\
\text { POINT CALCULATION }\end{array}$ \\
\hline PRNT & $\begin{array}{l}\text { PRE-WRITE DIRECT ACCESS UNITS IF NEEDED FOR POINT } \\
\text { CALCULATION }\end{array}$ \\
\hline PRNX & EDIT ATOM DENSITIES FOR POINT CALCULATION \\
\hline FRNZ & SETUP INITIAL DENSITIES FOR POINT CALCULATION \\
\hline PRN 3 & $\begin{array}{l}\text { PROCESS RTFLUX AND WRITE SELECTED POINT FLUXES ON } \\
\text { SCRATCH ONE GROUP AT A TIME FOR POINT CALCULATION } \\
\text { (METHOD 1) }\end{array}$ \\
\hline PRPE & $\begin{array}{l}\text { EDIT SPECIFIC REACTION RATE FOR FISSION IN ENERGY } \\
\text { RANGES OF YIELD DATA FOR POINT CALCULATION }\end{array}$ \\
\hline PRRI & $\begin{array}{l}\text { EDIT SPECIFIC REACTION RATE FOR FISSION IN ENERGY } \\
\text { RANGES OF YIELD DATA }\end{array}$ \\
\hline PRTD & PRINT DOUBLE PRECISION ARRAY \\
\hline PRTH & PRINT HOLLERITH ARRAY \\
\hline PRTI & PRINT INTEGER ARRAY \\
\hline PRTR & PRINT REAL ARRAY \\
\hline
\end{tabular}




\begin{tabular}{|c|c|}
\hline \multirow{3}{*}{$\begin{array}{l}\text { PRTT } \\
\text { PTAT }\end{array}$} & PRINT HOLLERITH TITLE \\
\hline & OBTAIN REFERENCE ZONE NUMBERS FROM PTATDN IF IT \\
\hline & EXISTS FOR POINT CALCULATION (METHOD 1) \\
\hline PTNS & $\begin{array}{l}\text { DETERMINE NUCLIDE SET AND INITIAL DENSITY INDEX } \\
\text { (ZONE OR SUBZONE) FOR POINT CALCULATION }\end{array}$ \\
\hline PURN & CONTROLS POINT EXPOSURE AND SHUTDOWN CALCULATION \\
\hline \multirow[t]{2}{*}{$\mathrm{PZT} 2$} & TEMPERATURES \\
\hline & CALCULATION) \\
\hline QNAT & WRITE INTERFACE FILE QNATDN \\
\hline \multirow[t]{2}{*}{ QNAW } & WRITE INTERFACE FILE ZNATDN (CONTINUOUS FUELING \\
\hline & EXPOSURE) \\
\hline REED & $\begin{array}{l}\text { ENTRY IN RITE - DATA TRANSFER (EXTERNAL DEVICE TO } \\
\text { MEMORY) }\end{array}$ \\
\hline $\mathrm{EHT}$ & CALCULATE REACTION RATE TYPE DATA FOR EXPOHT \\
\hline \multirow[t]{2}{*}{ REOR } & CHANGE VOLUME AND LOCATION DATA ORDER FOR POINT \\
\hline & CALCULATION (METHOD 1) \\
\hline RITE & DATA TRANSFER (MEMORY TO EXTERNAL DEVICE) \\
\hline ROXX & ENTRY IN RITE - SPECIAL ADDRESS INITIALIZATION \\
\hline ROXY' & ENTRY IN DOPC - SPECIAL ADDRESS INITIALIZATION \\
\hline RSTI & $\begin{array}{l}\text { FUNCTION TO ASSIGN AN INTEGER VARIABLE TO A REAL } \\
\text { VARIABLE LOCATION WITHOUT TYPE CONVERSION }\end{array}$ \\
\hline SEEK & INTERFACE FILE MANAGEMENT \\
\hline SERM & WRITE UNTERFACE FILE PROCESSING ERROR MESSAGE \\
\hline SKER & WRITE SEEK RELATED ERROR MESSAGE AND STOP \\
\hline \multirow[t]{3}{*}{ SKNU } & SUPPLEMENTAL \\
\hline & CHAINS NOT TO BE TREATED WITH MATRIX E: \\
\hline & OR AVERAGE GENERATION RATE METHODS \\
\hline \multirow{5}{*}{$\begin{array}{l}\text { STOR } \\
\text { TIMER }\end{array}$} & MOVE ARRAY Y TO ARRAY $X$ \\
\hline & MULTI-PURPOSE ROUTINE TO PROVIDE CPU TIME, CLOCK \\
\hline & TIME, CPU TIME REMAINING, I/O COUNT REMAINING, \\
\hline & COMPUTER MODEL, JOB NAME, \\
\hline & INFORMATION \\
\hline \multirow[t]{2}{*}{ TPNE } & NORMALIMATION \\
\hline & SUBSTEP TIMES, AND SHIJTDOWN SUBSET TIMES \\
\hline \multirow[t]{2}{*}{ VOLP } & COMPUTE REGION VOLUMES AND ZONE VOLUMES \\
\hline & $\begin{array}{l}\text { POINT VOLUMES FOR POINT CALCULATION (METHOD 1) } \\
\text { (DEBUG ONLY) }\end{array}$ \\
\hline $\mathrm{XE}$ & INITIALIZE AN ARRAY WITH A CONSTANT \\
\hline & MULTIPLY ARRAY X BY A CONSTANT \\
\hline $\mathrm{XE}$ & $\begin{array}{l}\text { MOVE DATA FROM ARRAY Y TO ARRAY X AND MULTI[PLY } \\
\text { BY A CONSTANT }\end{array}$ \\
\hline & ADD ARRAY \\
\hline
\end{tabular}




$\begin{array}{ll}\text { ZCRI } & \text { SUM BY ZONE CLASS ABSORPTIONS BY NUCLIDE CLASS, } \\ & \text { FISSILE ABSORPTIONS, FERTILE CAPTURES, FISSILE } \\ \text { ZFMP } & \text { DESTRUCTION RATE, AND FISSILE INVENTIRY } \\ & \text { PROCESS RZFLUX (MODIFIED) FOR ZONE NUMBERS AND } \\ \text { ZFMV } & \text { POINTS PER ZONE FOR POINT CALCULATION (METHOD 2) } \\ & \text { DUMMY VOLUME AND LOCATION DATA FOR POINT } \\ \text { ZFM3 } & \text { CALCULATION (METHOD 2) } \\ & \text { PROCESS RZFLUX (MODIFIED) AND WRITE POINT FLUYES } \\ \text { ZIGY } & \text { ON SCRATCH ONE GROUP AT A TIME FOR POINT } \\ \text { ZNAW } & \text { CALCULATION (METHOD 2) FTUP INTEGRATION RANGE FOR FISSION REACTION RATE } \\ \text { ZOND } & \text { WRITE INTERFACE FILE ZNATDN } \\ \text { ZONI } & \text { EDIT ATOM DENSITIES FOR ONE ZONE /SUBZONE } \\ \text { ZUCY } & \text { ACCUMULATE MASS RATES IN KG/SEC } \\ \text { ZUCZ } & \text { CHECK AND EDIT EXPLICIT CHAIN DATA } \\ \text { ZZPD } & \text { DETERMINE MAXIMUM EXPLICIT CHAIN LENGTH } \\ \text { ZZPF } & \text { EDIT ZONE POWER DENSITY AND WRITE INTERFACE FILE } \\ & \text { ZNPOWD } \\ & \text { CALCULATE ACTINIDE FEED RATE (KG/SEC) BY PATH FOR } \\ & \text { CONTINUOUS FUELING MODEL }\end{array}$



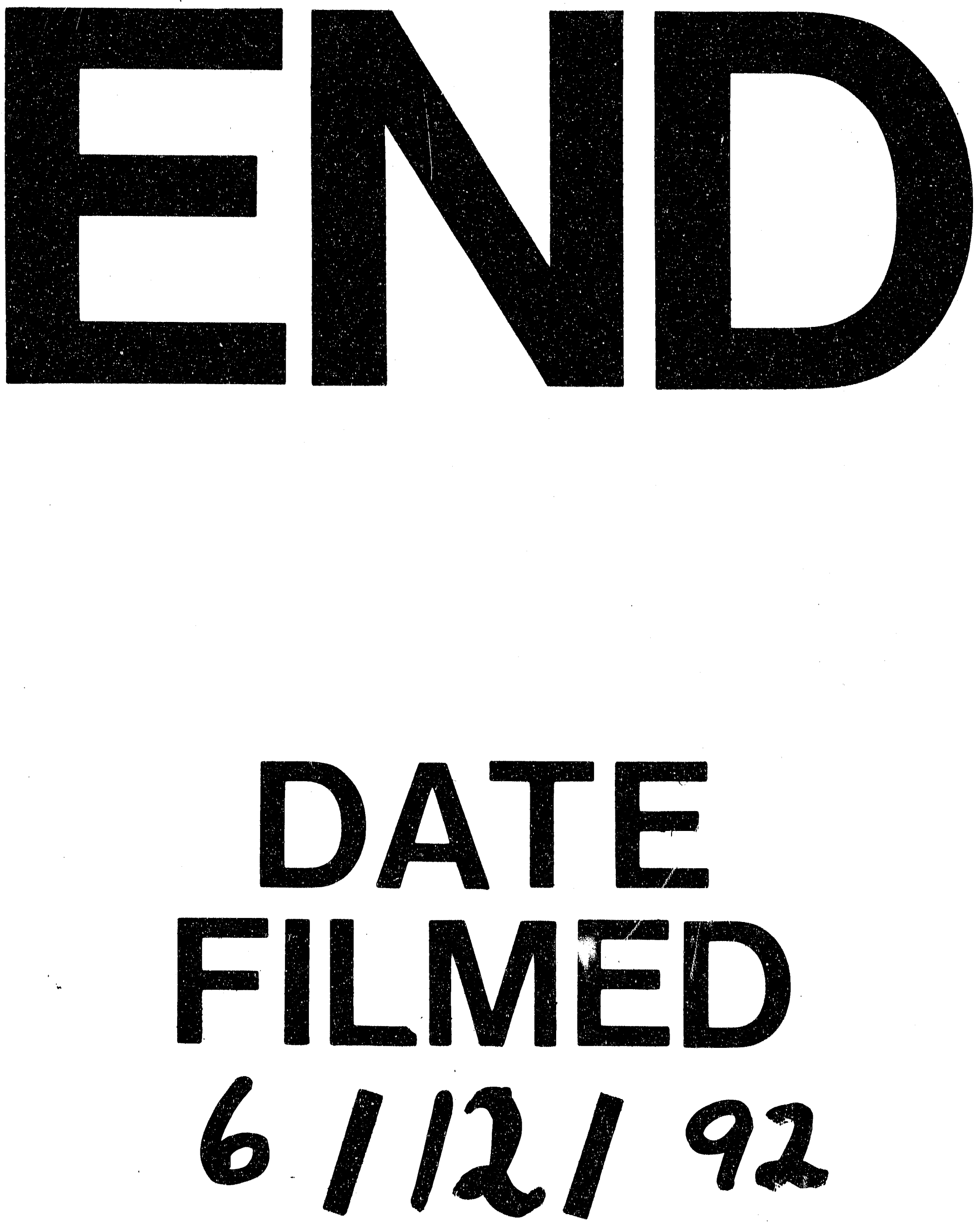
